\title{
Demographic Change, Human Capital and ENDOGENOUS GROWTH
}

\author{
Alexander Ludwig, Thomas Schelkle and
} Edgar Vogel

$151-2007$

๑ $\boldsymbol{m e a - M a n n h e i m ~ R e s e a r c h ~ I n s t i t u t e ~ f o r ~ t h e ~ E c o n o m i c s ~ o f ~ A g i n g ~}$

L13, 17_D-68131 Mannheim_Phone +49 621 181-2773/1862_Fax +49 621 181-1863_www.mea.uni-mannheim.de 


\title{
Demographic Change, Human Capital and Endogenous Growth*
}

\author{
Alexander Ludwig ${ }^{\dagger}$ \\ MEA, University of Mannheim \\ Thomas Schelkle \\ London School of Economics \\ Edgar Vogel \\ MEA, University of Mannheim
}

This version: August 10, 2007

\begin{abstract}
This paper employs a large scale overlapping generations (OLG) model with endogenous education to evaluate the quantitative role of human capital adjustments for the economic consequences of demographic change. We find that endogenous human capital formation is an important adjustment mechanism which substantially mitigates the macroeconomic impact of demographic change. Welfare gains from demographic change for newborn households are approximately three times higher when households endogenously adjust their education. Low ability agents experience higher welfare gains. Endogenous growth through human capital formation is found to increase the long-run growth rate in the economy by $0.2-0.4$ percentage points.
\end{abstract}

JEL classification: E17, E25, D33, C68, J11, J24

Keywords: population aging; human capital; endogenous growth; heterogenous agents; distribution of welfare

${ }^{*}$ We thank Dirk Krüger, Wolfgang Kuhle and Matthias Weiss for helpful discussions and several seminar participants at Universität Frankfurt, Universität Mannheim and at the $13^{\text {th }}$ International Conference of the Society for Computational Economics in Montreal for helpful comments. Financial support by the German National Research Foundation (DFG) through SFB 504, the State of Baden-Württemberg and the German Insurers Association (GDV) is gratefully acknowledged.

${ }^{\dagger}$ Corresponding author: Alexander Ludwig; Mannheim Research Institute for the Economics of Aging (MEA); Universität Mannheim; L13, 17; 68131 Mannheim; Phone: ++49-621-181-1866; Fax: ++49-621-181-1863; Email: ludwig@mea.unimannheim.de. 


\section{Introduction}

As in all major industrialized countries the population of the United States is aging over time. This process is driven by increasing life-expectancy and a decline in birth rates. Consequently, the fraction of the population in working-age will decrease and the fraction of people in oldage will increase. Based on population projections from the United Nations (2002), figure 1 illustrates the impact of demographic change on the population growth rate and the workingage population ratio - the ratio of the working-age population (of age 20-64) to the total adult population (of age 20-90) - in the U.S.. The working age population ratio decreases from $83 \%$ in 2007 to $72 \%$ in 2075 ; the population growth rate is expected to decline from $0.9 \%$ per year in 2007 to $0.5 \%$ in 2075 .

Figure 1: Working Age Population Ratio and Population Growth in the United States

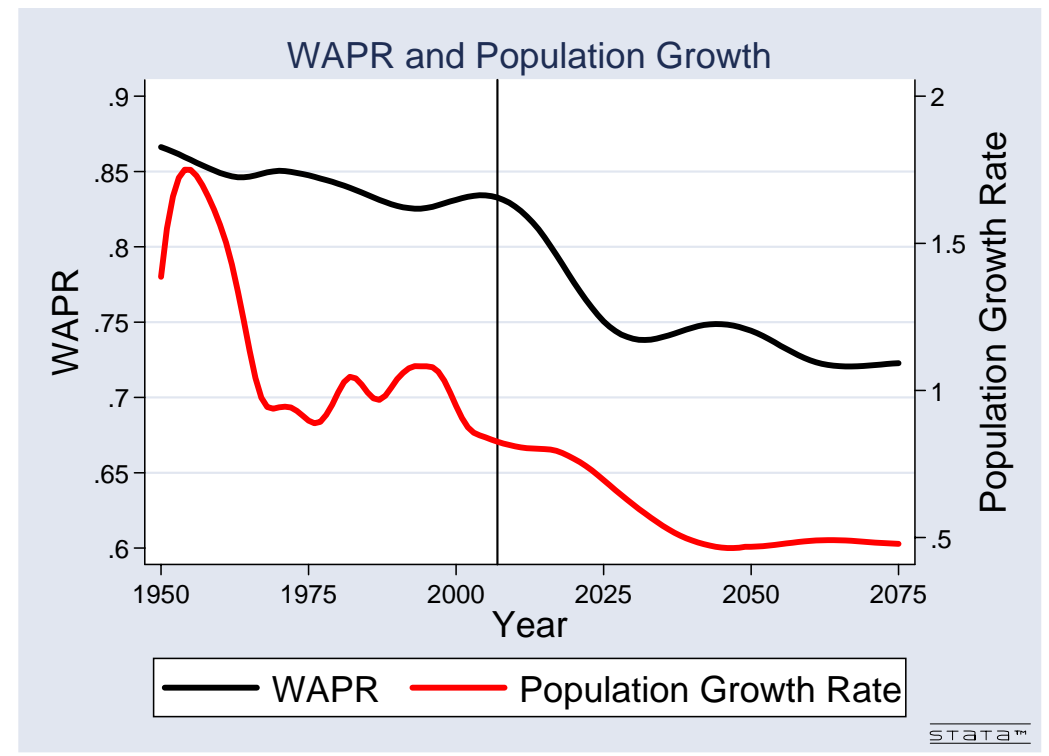

These projected changes in the population structure will have important macroeconomic effects on the balance between physical capital and labor. Specifically, labor is expected to be scarce, relative to capital, with an ensuing decline in real returns on capital and increases in gross wages. In the public debate it has been argued that better education could be an im- 
portant factor to compensate for this scarcity of labor. This paper analyzes how demographic change affects the incentives to invest in human capital and the interaction between human capital formation, economic growth, social security and the distribution of welfare. We show that adjustments in human capital investments substantially mitigate the macroeconomic impact of demographic change with profound implications for individual welfare.

The key mechanism at work in our paper is that scarcity of raw labor and abundance of physical capital will lead to an increase of the relative return to education which, in a model with endogenous education decisions, leads to increased human capital investment. That this adjustment mechanism is indeed at work is supported by the indirect empirical evidence in Heckman et al. (1998), who test an OLG model with endogenous human capital formation by accounting for the U.S. baby boom, and the stylized fact that college attendance has increased in the 1980s as a response to the increase in the college wage premium (Heckman and Carneiro 2003).

In order to quantify the effects of human capital formation in the aging U.S. society, we develop a large scale OLG-model as an extension of the Auerbach and Kotlikoff (1987) model with endogenous labor supply and educational decisions as well as endogenous growth. We work out the differences to standard models without human capital by proposing three different models with increasing degree of sophistication. We start with a standard model where agents only make consumption-saving decisions and endogenously supply raw labor. In a next step, we allow agents to invest time into human capital formation. Finally, we endogenize growth by introducing a Lucas (1988) type growth mechanism through intergenerational transmission of human capital. ${ }^{1}$ Throughout we address the role played by social security

\footnotetext{
${ }^{1}$ We exclusively focus on human capital accumulation as the source of long-run growth and do not consider investments in R\&D and technological innovations as in Romer (1990), Grossman and Helpman (1991), Aghion and Howitt (1992) and their followers.
} 
in an aging population by analyzing how the policy evaluation of a social security system with constant contribution rates is affected by the endogenous human capital formation. Furthermore, we analyze the welfare consequences of demographic change across skill types that emanate from the evolution of factor prices and therefore model intra-generational heterogeneity. ${ }^{2}$ As heterogeneity in human capital endowments and learning abilities at young ages rather than shocks to human capital explain observed moments of income distributions and account for up to $90 \%$ of the variation in total lifetime utility (Huggett et al. 2006; Huggett et al. 2007; Keane and Wolpin 1997), we model intra-cohort heterogeneity through differences across household types in initial stocks and type-specific learning abilities but abstain from shocks to human capital.

The main finding of this paper is that endogenous human capital formation is an important channel to adjust to demographic change. Including endogenous education decisions into the model leads to profoundly different quantitative implications for the evolution of relative factor prices and the resulting welfare consequences than the standard model with only physical capital and raw labor. Welfare consequences from the increase in wages and declines in rates of return can be substantial, in the order of up to $1 \%$ in lifetime consumption for newborns in 2005 when contribution rates to the pension system are held constant. We also find that newborn low ability agents experience slightly higher welfare gains than high ability agents. In contrast, households that have already accumulated assets loose from the decline in rates of return. Most importantly, we find that welfare gains are substantially higher in the human capital augmented model relative to the standard model. The overall mass of agents alive in 2005 that benefit from demographic change increases from $11 \%$ to almost $40 \%$ when we move from the standard model to the human capital augmented models. At the same time, the

\footnotetext{
${ }^{2}$ To this end we focus on the pure effects of changes in relative factor prices and not on skill bias of technological change (Heckman et al. 1998; Aghion et al. 1999).
} 
maximum loss for middle aged agents decreases from $-0.7 \%$ to $-0.4 \%(-0.2 \%)$ in the model with endogenous education (and endogenous growth). While we do not find that additionally making growth endogenous has a large effect on relative factor prices in the period of the demographic transition, endogenous growth leads to an increase of the long-run growth rate of labor productivity by 0.2 to 0.4 percentage points.

Our model borrows model elements from and contributes to several strands of the literature. Based on the seminal contribution of Auerbach and Kotlikoff (1987) a vast number of papers have analyzed the economic consequences of population aging, often paying particular attention to the pressure on social security systems. Important examples in closed economies include Huang et al. (1997), De Nardi et al. (1999) and, with respect to migration, Storesletten (2000). In open economies, Börsch-Supan et al. (2006), Attanasio et al. (2007) and Krüger and Ludwig (2007), among others, investigate the role of international capital flows during the demographic transition. We add to this literature by extending the standard model to endogenous education and thus by analyzing a different mechanism through which households can respond to demographic change. Since Krüger and Ludwig (2007) report that the effects of openness on relative factor prices are small from a U.S. perspective, we work with a closed economy model.

Our paper is most closely related to the theoretical work by de la Croix and Licandro (1999), Boucekkine et al. (2002), Echevarria and Iza (2006) and Heijdra and Romp (2007) on longevity, human capital, taxation and endogenous growth and the quantitative work in Fougère and Mérette (1999) and Sadahiro and Shimasawa (2002) who also investigate demographic change in large-scale OLG models with individual human capital decisions and an endogenous growth mechanism. ${ }^{3}$ We extend their analysis along various dimensions. We

\footnotetext{
${ }^{3}$ Similar models have been used by Hendriks (1999) and Bouzahzah et al. (2002) to address the effects of taxation and
} 
use realistic demographic projections based on the United Nations (2002) instead of stylized scenarios. Our model also contains a labor/education-leisure trade-off. Thus, it can capture effects from changes in individual labor supply, i.e. human capital utilization, on the return of human capital investments. We calibrate our model such that it replicates realistic human capital profiles over the life-cycle for different ability groups. Furthermore, we put particular emphasis on the welfare consequences of population aging, both for different generations living through the demographic transition as well as for different skill groups. To this end, our model also contains intra-cohort heterogeneity with respect to initial human capital stocks and learning abilities.

The paper is organized as follows. In section 2 we construct a simple two period model to illustrate the basic mechanisms at work in our quantitative model which is introduced in section 3. Section 4 describes the calibration strategy and our computational solution method. Our results are presented in section 5. Finally, section 6 concludes the paper.

\section{$2 \quad$ A Simple Model}

In this section we develop a simple two period model with endogenous education decisions and a PAYG financed social security system. We distinguish between two scenarios, one with exogenous growth and another with a Lucas (1988)-type growth mechanism at work. The setup is as follows: agents live for two periods, in the first period they choose time investment into education, saving and consumption. In the second period they consume their entire wealth and work a fraction $\omega$ of their time. The rest of their time $(1-\omega)$ they are retired and

other government policies on human capital formation and economic growth. Our analysis is also related to Heer and Irmen (2007) who, in an otherwise similar setup as ours, analyze the role of endogenous growth through labor-saving technical change. 
receive a lump-sum pension $p_{t}$.

\subsection{Household Optimization}

Households maximize lifetime utility

$$
\max _{c_{t}^{y}, c_{t+1}^{o}} \log c_{t}^{y}+\beta \log c_{t+1}^{o}
$$

with $\beta$ being the discount factor and the superscripts $y$ (young) and $o$ (old) denote the two periods of life. The sequential budget constraints are

$$
\begin{aligned}
c_{t}^{y}+s_{t}^{y} & =\left(1-e_{t}\right) h_{t}^{y} w_{t}\left(1-\tau_{t}\right) \\
c_{t+1}^{o} & =\left(1+r_{t+1}\right) s_{t}^{y}+\omega h_{t+1}^{o} w_{t+1}\left(1-\tau_{t+1}\right)+(1-\omega) p_{t+1},
\end{aligned}
$$

where $e_{t}$ is investment into education when young, $h_{t}^{y}$ is the stock of human capital given at birth, $w_{t}$ is the wage rate, $r_{t+1}$ is the return on financial assets, $\tau_{t}$ denotes the social security contribution rate, $p_{t}$ are lump-sum pension payments and $s_{t}^{y}$ is savings. The present value budget constraint is accordingly given by

(4) $c_{t}^{y}+\frac{c_{t+1}^{o}}{1+r_{t+1}}=\left(1-e_{t}\right) h_{t}^{y} w_{t}\left(1-\tau_{t}\right)+\omega \frac{\left.h_{t+1}^{o} w_{t+1}\left(1-\tau_{t+1}\right)\right)}{1+r_{t+1}}+(1-\omega) \frac{p_{t+1}}{1+r_{t+1}}$.

The education technology is

$$
h_{t+1}^{o}=\left(1+g\left(e_{t}\right)\right) h_{t}^{y}
$$

with $g$ being a function mapping educational investment into formation of human capital. We choose $g$ such that it is increasing, concave in $e$ and fulfills the lower Inada condition. Solving the maximization problem gives the usual Euler equation

$$
c_{t+1}^{o}=\beta\left(1+r_{t+1}\right) c_{t}^{y} .
$$


Solving for the optimal educational investment gives

$$
g^{\prime}\left(e_{t}\right)=\left(1+r_{t+1}\right) \frac{w_{t}\left(1-\tau_{t}\right)}{w_{t+1}\left(1-\tau_{t+1}\right)}
$$

Defining the education function $g\left(e_{t}\right)$ in $(5) \mathrm{as}^{4}$

$$
g\left(e_{t}\right)=\xi e_{t}^{\psi}
$$

where $\xi>0$ and $0<\psi<1$, optimal education is determined by

$$
e_{t}=\left[\omega \xi \psi \frac{w_{t+1}\left(1-\tau_{t+1}\right)}{w_{t}\left(1-\tau_{t}\right)} \frac{1}{1+r_{t+1}}\right]^{\frac{1}{1-\psi}}
$$

It can be seen that educational decisions depend on the ratio of net wage growth to the return on capital holdings and on the fraction of time working in the second period. The relevant scenario in the presence of scarce labor and abundant capital is one with rising wages and falling interest rates. This will induce an increase in education and an increase in the growth rate of human capital.

Finally, households' optimal consumption follows from combining (6) and (5) in (4) and savings are accordingly given by

$$
s_{t}^{y}=\frac{1}{1+\beta}\left(\beta\left(1-e_{t}\right) h_{t}^{y} w_{t}\left(1-\tau_{t}\right)-\frac{\omega\left(1+g\left(e_{t}\right)\right) h_{t}^{y} w_{t+1}\left(1-\tau_{t+1}\right)+(1-\omega) p_{t+1}}{1+r_{t+1}}\right) .
$$

\section{$2.2 \quad$ Firms}

Firms produce output using a standard Cobb-Douglas production function

$$
Y_{t}=K_{t}^{\alpha}\left(A_{t} L_{t}\right)^{1-\alpha}
$$

$A_{t}$ is the firm's technology level, which, in the exogenous growth specification of our model, grows with the gross rate of $\gamma^{A}=1+g^{A}$. Competitive markets ensure that factors get paid

\footnotetext{
${ }^{4}$ In our quantitative model of section 3 we use the same functional form.
} 
their marginal products. We assume that capital depreciates fully after one period such that

$$
\begin{aligned}
1+r_{t} & =\alpha k_{t}^{\alpha-1} \\
w_{t} & =(1-\alpha) A_{t} k_{t}^{\alpha},
\end{aligned}
$$

where $k_{t}=\frac{K_{t}}{A_{t} L_{t}}$.

\subsection{Social Security}

The social security system is organized on a PAYG basis such that the budget is balanced in every period which gives

$$
w_{t}\left(1-e_{t}\right) h_{t}^{y} \tau_{t} N_{t}^{y}+\omega w_{t} h_{t}^{o} \tau_{t} N_{t}^{o}=(1-\omega) p_{t} N_{t}^{o}
$$

where $N_{t}^{y}$ and $N_{t}^{o}$ denote the size of the young and old generation. Without mortality risk we have $N_{t+1}^{o}=N_{t}^{y}$ and defining $\gamma_{t}^{N}=1+g_{t}^{N}$ as the (possibly time varying) growth rate of population it holds that $N_{t}^{y}=\gamma_{t}^{N} N_{t}^{o}$.

Changes in the population structure $\gamma^{N}$ require adjustments of the social security policy. Let $\rho_{t}$ denote the replacement rate (the ratio of pension income to average net wage income). Then pension income can be expressed as

$$
p_{t}=\rho_{t} \frac{\left(1-\tau_{t}\right) w_{t}\left(\left(1-e_{t}\right) h_{t}^{y} N_{t}^{y}+\omega h_{t}^{o} N_{t}^{o}\right)}{N_{t}^{y}+\omega N_{t}^{o}} .
$$

Using the above in (14) and simplifying then links contribution and replacement rates by

$$
\tau_{t}=\frac{(1-\omega) \rho_{t}}{\omega+\gamma_{t}^{N}+(1-\omega) \rho_{t}} .
$$

It can be readily observed that $\tau_{t}$ increases in the fraction of pensioners, $1-\omega$, the generosity of the pension system, $\rho_{t}$, and decreases in the population growth rate, $\gamma_{t}^{N}$. 


\subsection{Equilibrium}

In equilibrium all markets clear, households maximize utility and firms make zero profits. This requires that

$$
\begin{aligned}
K_{t+1} & =s_{t}^{y} N_{t}^{y} \\
L_{t} & =N_{t}^{o} h_{t-1}^{y}\left[\left(1-e_{t}\right) \gamma_{t}^{N} \gamma_{t}^{h}+\omega\left(1+g\left(e_{t-1}\right)\right)\right] .
\end{aligned}
$$

In the endogenous growth specification it is assumed that newborn generations inherit human capital from older generations according to

$$
h_{t}^{y}=\mu h_{t}^{o}=\mu h_{t-1}^{y}\left(1+g\left(e_{t-1}\right)\right),
$$

with $\mu$ as the human capital transmission factor. Hence, the growth rate of human capital is

$$
\gamma_{t}^{h}=\frac{h_{t}^{y}}{h_{t-1}^{y}}=\mu\left(1+g\left(e_{t-1}\right)\right)
$$

Note that in the endogenous specification of the model, the source of technological progress is only learning (not learning by doing) and transmission of human capital. In the exogenous growth model we set $\gamma_{t}^{h}=1$ and $A$ grows at an exogenously determined rate $\gamma^{A}$. Using (18) and (19) in (17), we obtain

$$
L_{t}=N_{t}^{o} h_{t-1}^{y}\left(\left(1-e_{t}\right) \gamma_{t}^{N} \gamma_{t}^{h}+1+g\left(e_{t-1}\right)\right)
$$

for the aggregate labor supply. Dividing equation (16) by $A_{t+1} L_{t+1}$, using (10) and (20) and rearranging terms then gives the law of motion for capital per effective worker as

$$
(21) k_{t+1}=\frac{\alpha(1-\alpha) \beta\left(1-e_{t}\right)\left(1-\tau_{t}\right)}{\gamma^{A}\left[\left(\alpha(1+\beta)+(1-\alpha) \tau_{t+1}\right)\left(1-e_{t+1}\right) \gamma_{t+1}^{N} \gamma_{t+1}^{h}+\omega(1+\alpha \beta)\left(1+g\left(e_{t}\right)\right)\right]} k_{t}^{\alpha} .
$$

Furthermore, using (8) and (12) in (9) gives the optimal education decision as

$$
e_{t}=\left[\omega \xi \psi \frac{\gamma^{A}\left(1-\tau_{t+1}\right) k_{t+1}}{\alpha\left(1-\tau_{t}\right) k_{t}^{\alpha}}\right]^{\frac{1}{1-\psi}} .
$$




\subsection{Steady State Analysis}

The question of interest is how capital per effective worker, wages, interest rates and investment into education are affected by demographic change. To analyze this, we assume that the economy is in steady state and vary the population structure $\gamma^{N}$. Note that $\gamma^{N}$ is not only the population growth factor but because of $N^{y}=\gamma^{N} N^{o}$, it is also the ratio of young to old, or, the inverse of the old age dependency ratio. Thus, by decreasing $\gamma^{N}$ we simulate the coming demographic change and can derive some qualitative predictions for our quantitative model.

As we focus on steady states, we drop time indices. Here we assume that the replacement rates adjusts and write the steady state relationships from equations (21), (22) and (15) as

$$
\begin{aligned}
k= & \Omega\left(e, \gamma^{N}, \tau\right)^{\frac{1}{1-\alpha}} \\
e= & {\left[\omega \psi \xi \frac{\gamma^{A}}{\alpha} \Omega\left(e, \gamma^{N}, \tau\right)\right]^{\frac{1}{1-\psi}} } \\
\Omega\left(e, \gamma^{N}, \tau\right) \equiv & \frac{\alpha(1-\alpha) \beta(1-e)(1-\tau)}{\gamma^{A}\left[(\alpha(1+\beta)+(1-\alpha) \tau)(1-e) \gamma^{N} \gamma^{h}+(1+\alpha \beta)(1+g(e))\right]} \\
\tau \equiv & \frac{(1-\omega) \rho}{\omega+\gamma^{N}+(1-\omega) \rho} .
\end{aligned}
$$

Recall that

$$
\gamma^{h}= \begin{cases}\mu(1+g(e)) & \text { for endogenous growth } \\ 1 & \text { for exogenous growth. }\end{cases}
$$

A number of qualitative conclusions can be derived from these steady state relationships (cf. appendix A.2 for details). First, for our scenario where $\tau$ is held constant, it follows that

$$
\frac{\partial k}{\partial \gamma^{N}}<0, \quad \frac{\partial e}{\partial \gamma^{N}}<0
$$


for both the exogenous and the endogenous growth specification. Thus, the prediction of our simple model is that in an ageing society we have to expect higher capital intensity and rising educational attaintment. A higher share of older individuals decreases labor relative to capital and therefore $k$ will rise. In steady state, a higher capital stock per effective worker does not affect the wage growth between two periods but decreases the interest rate. ${ }^{5}$ It then follows from (9) that optimal educational investment will rise.

Second, we derive that

$$
\frac{\partial k}{\partial \tau}<0, \quad \frac{\partial e}{\partial \tau}<0
$$

With increasing $\tau$, savings will be crowded out and the physical capital stock will therefore be lower. As a consequence of the lower capital stock, educational investment will also be lower which can be directly observed from (9). This is the direct effect of higher taxation on $k$ and $e$.

Third, repeating the comparative statics of variations in $\gamma^{N}$ from above and holding replacement rates constant (adjusting contribution rates), we can no longer determine the sign of the partial derivatives in (25), because the direct effect of changing $\gamma^{N}$ and the indirect effect through adjustments of the contribution rate are of opposite sign and we cannot derive which out of the two effects dominates. Numerically calculating steady states in the simple model using reasonable parametrization, we however found that the partial derivatives in (25) are smaller (in absolute values) in the case of constant replacement rates but still negative. ${ }^{6}$ We can therefore conclude that keeping the replacement rate constant and thus increasing

\footnotetext{
${ }^{5}$ To be precise, in the endogenous specification steady state growth will be affected by the design of the social security system because the educational investment is a function of taxes. However, the argument from above is even reinforced in the endogenous growth scenario because higher taxes lead to lower $k$, rising interest rates and less education. Thus, the decrease in the incentive to invest in education is even stronger.

${ }^{6}$ These results are available upon request.
} 
the social security contribution rate when $\gamma^{N}$ falls, leads to lower capital intensity and lower educational investment than in the scenario with constant contribution rates. Consequently, this case also implies a lower long run growth rate than in the endogenous growth specification of our model.

Finally, observe from (24), (23c) and (23b) that, in the endogenous growth model, the time invested into education is a decreasing function of $\mu$ - the parameter capturing the intergenerational transmission of human capital - because the effect of $\mu$ is mathematically identical to $\gamma^{N}$ (when we hold contribution rates constant). The insight that optimal education decreases in $\mu$ can be interpreted on the grounds that $\mu$ is a measure for the degree of (positive) externality of human capital. This intergenerational spill-over accelerates the growth rate which in turn depresses capital per effective worker and raises interest rates. Furthermore, notice that for $\gamma^{h}=\mu(1+g(e))>1$, educational investment will be absolutely lower in the endogenous than in the exogenous growth model.

\section{The Quantitative Model}

In this section we introduce the quantitative model that we use to evaluate the economic consequences of demographic change. We employ a large scale Overlapping Generations Model à la Auerbach and Kotlikoff (1987) with heterogenous agents. The structure of our model, which we describe in detail in the following subsections, is similar to the simple model of the previous section but we extend the simplified setup by endogenous labor supply and heterogeneity of households with respect to the human capital technology. 


\subsection{Timing, Demographics and Notation}

Time is discrete and one period corresponds to one calender year $t$ extending from $t=$ $0, \ldots, \infty$. Each year, a new generation is born. Birth in this paper refers to the first time households make own decisions and is set to real life age of 16 (model age $j=0$ ). Agents retire at an exogenously given age of 66 (model age $j r=50$ ), i.e. the last year of labor force participation is at age 65. The maximum life expectancy is set to 90 (model age $j=J=74$ ) and agents face survival risk. At a given point in time $t$, individuals of age $j$ will survive to age $j+1$ with probability $\varphi_{t, j}$ where $\varphi_{t, 0}=1$ and $\varphi_{t, J+1}=0$. Unconditional survival probabilities are denoted by $\pi_{t, j}=\prod_{k=0}^{j} \varphi_{t, k}$. The number of agents of age $j$ at time $t$ is denoted by $N_{t, j}$. Since we introduce intra-cohort heterogeneity we use the additional index $i$ to denote type specific values.

\subsection{Endowments, Preferences and Constraints}

Each household of type $i$ comprises of one representative worker who decides about consumption and saving, supply of labor and educational investment. The household maximizes lifetime utility at the beginning of economic life in period $t$,

$$
\max \sum_{j=0}^{J} \beta^{j} \pi_{t+j, j} u\left(c_{t+j, j, i}, 1-\ell_{t+j, j, i}-e_{t+j, j, i}\right), \quad \forall i
$$

where the period utility function $u(c, 1-\ell-e)$ is a function of individual consumption $c$, labor supply $\ell$ and time investment into formation of human capital $e . \beta$ is the pure time discount factor and $\pi_{t, j}$ denotes the unconditional survival probabilities. The per period utility function is given by

$$
u(c, 1-\ell-e)=\frac{1}{1-\sigma}\left\{c^{\phi}(1-\ell-e)^{1-\phi}\right\}^{1-\sigma}, \quad \sigma>0 \phi \in(0,1),
$$


where $\sigma$ and $\phi$ denote the coefficient of relative risk aversion and the weight of consumption in utility, respectively.

Agents receive income from working on the labor market, earn interest payments on their savings and receive pension payments when retired. When working they have to pay contributions $\tau_{t}$ to the social security system. The net wage income in period $t$ of an agent of age $j$ and ability group $i$ is given by

$$
w_{t, j, i}^{n}=\ell_{t, j, i} h_{t, j, i} w_{t}^{g}\left(1-\tau_{t}\right) \quad \forall i
$$

where $w_{t}^{g}$ is the (gross) wage per unit of supplied human capital at time $t$. Here, we assume that human capital is a homogenous input, i.e. human capital of different cohorts and types are perfect substitutes. ${ }^{7}$

Due to age dependent survival probabilities agents leave accidental bequests. These are confiscated by the government and returned to the households as lump-sum payments (transfers) which we denote by $t r_{t}$. Transfers are the same for every living household and do not depend on age or type. Accordingly, the dynamic budget constraint is given by

$$
a_{t+1, j+1, i}= \begin{cases}\left(a_{t, j, i}+t r_{t}\right)\left(1+r_{t}\right)+w_{t, j, i}^{n}-c_{t, j, i} \quad \text { if } j<j r \quad \forall i \\ \left(a_{t, j, i}+t r_{t}\right)\left(1+r_{t}\right)+p_{t, j, i}-c_{t, j, i} \quad \text { if } j \geq j r \quad \forall i\end{cases}
$$

where $a_{t, j, i}$ denotes assets, $r_{t}$ the real interest rate, $t r_{t}$ are transfers and $p_{t, j, i}$ pensions in period $t$, age $j$.

\subsection{Formation of Human Capital}

A key element of our model is endogenous formation of human capital via time investment into education. There is a considerable amount of consensus in the profession about a reasonable set

\footnotetext{
${ }^{7}$ By the assumption of perfect substitutability we focus on the distributional effects of changes in relative factor prices only and ignore potential effects of skill bias of technological change as analyzed in (Heckman et al. 1998).
} 
of production functions on the aggregate level. Unfortunately, there is a lot of disagreement as to how knowledge is "produced". In this paper, we adopt the functional form of the education technology from Bouzahzah et al. (2002) which we already used in our simple model of section 2.

Households enter economic life with a predetermined level of human capital $h_{t, 0, i}$. Afterwards, they can work and invest a fraction of their time into acquiring additional human capital. The education technology is

$$
h_{t+1, j+1, i}=h_{t, j, i}\left(1+\xi_{i} e_{t, j, i}^{\psi_{i}}-\delta_{i}^{h}\right), \quad \psi_{i} \in(0,1), \quad \xi_{i}>0, \quad \delta_{i}^{h} \geq 0
$$

where $\xi_{i}$ is a scaling factor and $\psi_{i}$ determines the curvature of the education technology, $\delta_{i}^{h}$ is the depreciation rate of human capital and $e_{t-j, j, i}$ is time investment into acquiring human capital. The costs of investing into education in this model are only the opportunity costs of foregone wage income. The growth rate of the human capital is given by

$$
\begin{aligned}
g_{t, j, i}^{h} & =\frac{h_{t+1, j+1, i}-h_{t, j, i}}{h_{t, j, i}} \forall i \\
& =\xi_{i} e_{t, j, i}^{\psi_{i}}-\delta_{i}^{h}
\end{aligned}
$$

and is thus independent of the stock of human capital.

We understand the process of accumulating human capital as a mixture of knowledge acquired by formal schooling and on the job or training programmes after schooling. A direct implication is that "education" does not only refer to time spent in the formal school system but has to be understood in a broader perspective. Human capital is accumulated only up to an exogenously defined age $j h$ and depreciates afterwards at a constant rate. 


\subsection{The Growth Specification}

As in our simple model of section 2, we consider two different growth specifications. The exogenous model is specified by using a labor-augmenting form of technical progress

$$
A_{t+1}=A_{t}\left(1+g^{A}\right)
$$

where $g^{A}$ is the exogenously specified growth rate of labor productivity. The opposite scenario that we look at is that technological progress in the long run is driven entirely by the accumulation of human capital. Human capital is transmitted between generations according to

$$
h_{t, 0, i}=\mu \zeta_{i} \frac{\sum_{j=S_{1}}^{S_{2}} \sum_{i=1}^{I} h_{t-1, j, i} N_{t-1, j, i}}{\sum_{j=S_{1}}^{S_{2}} \sum_{i=1}^{I} N_{t-1, j, i}}, \quad \mu>0, \quad \zeta_{i}>0
$$

where $S_{1}$ and $S_{2}$ determine the range of cohorts whose human capital is transmitted to the new generations, $\mu$ is the human capital transmission factor and $\zeta_{i}$ determines the distribution of initial human capital for a newborn generation. ${ }^{8}$

By this specification we assume that human capital is non-rival when it is transmitted to a new generation. ${ }^{9}$ It is a public good that every agent inherits at the beginning of her life and could be equally well interpreted as the average general skill level of the society (Lucas 1988, p. 17). However, human capital is embodied in all individuals and is therefore rival (and can be used exclusively by one person) when it comes to be utilized in the production process.

The parameter $\mu$ can be interpreted as the capacity of the society to pass on the available stock of knowledge embodied in the population to the next newborn generation. Put differently, it proxies the ability of the educational system to disembody the human capital

\footnotetext{
${ }^{8}$ This specification corresponds to Lucas $(1988)$ in a framework with finitely lived agents. Note that on the aggregate level we do not incorporate average human capital into the production function (see section 3.5).

${ }^{9}$ This is why newborns receive an amount from average human capital and not a share from the total stock.
} 
of currently living generations. Human capital can grow without bound and is the source of long-run growth. In the endogenous growth specification, we set $g^{A}=0$ and normalize $A_{t}=1 \forall t$.

\section{$3.5 \quad$ Firms}

Firms operate in a perfectly competitive environment and produce one homogenous good according to the Cobb-Douglas production function

$$
Y_{t}=K_{t}^{\alpha}\left(A_{t} L_{t}\right)^{1-\alpha}
$$

where $\alpha$ denotes the share of capital used in production. $K_{t}, L_{t}$ and $A_{t}$ are the stocks of physical capital, effective labor and the level of technology, respectively. Output can be either consumed or used as an investment good. We assume that labor inputs of different skill levels and ages are perfect substitutes and effective labor input $L_{t}$ is accordingly given by

$$
L_{t}=\sum_{j=0}^{j r-1} \sum_{i=1}^{I} \ell_{t, j, i} h_{t, j, i} N_{t, j, i} .
$$

Factors of production are paid their marginal products,

$$
\begin{array}{r}
w_{t}^{g}=(1-\alpha) \frac{Y_{t}}{L_{t}} \\
r_{t}=\alpha \frac{Y_{t}}{K_{t}}-\delta,
\end{array}
$$

where $w_{t}^{g}$ is the gross wage per unit of efficient labor, $r_{t}$ is the interest rate and $\delta$ denotes the depreciation rate of physical capital.

\subsection{The Pension System}

The pension system is a simple balanced budget pay-as-you-go system. Workers contribute a fraction $\tau_{t}$ of their gross wages and pensioners receive a fraction $\rho_{t}$ of the current average 
net wages of the individuals of their own type. While pension benefits are lump-sum as in a Beveridge system, the scope for intra-generational redistribution is limited by their type dependency. ${ }^{10}$ The level of pensions in each period is then given by

$$
p_{t, j, i}=\rho_{t}\left(1-\tau_{t}\right) w_{t}^{g} \frac{\sum_{j=0}^{j r-1} \ell_{t, j, i} h_{t, j, i} N_{t, j, i}}{\sum_{j=0}^{j r-1} \ell_{t, j, i} N_{t, j, i}} . \forall i
$$

In our benchmark scenario we assume that the contribution rate is fixed and adjust the replacement rate such that the budget of the social security system is balanced every period.

Hence,

$$
\tau_{t} w_{t}^{g} \sum_{j=0}^{j r-1} \sum_{i=1}^{I} \ell_{t, j, i} h_{t, j, i} N_{t, j, i}=\sum_{j=j r}^{J} \sum_{i=1}^{I} p_{t, j, i} N_{t, j, i} \quad \forall t
$$

\subsection{Equilibrium}

At the beginning of every period $t$, households solve the maximization problem

$$
V_{t}\left(a_{t}, h_{t}\right)=\max _{c_{t}, \ell_{t}, e_{t}, a_{t+1}, h_{t+1}}\left\{u\left(c_{t}, 1-\ell_{t}-e_{t}\right)+\varphi_{t} \beta V_{t+1}\left(a_{t+1}, h_{t+1}\right)\right\}
$$

subject to the dynamic and present value budget constraints.

Definition 1. Given the initial capital stock, average human capital and distribution of types $\left\{K_{0},\left\{h_{0, i}\right\}_{i=1}^{I}, \Phi_{0}\right\}$, a competitive equilibrium are sequences of individual variables $\left\{\left\{\left\{c_{t, j, i}, \ell_{t, j, i}, e_{t, j, i}, a_{t, j, i}, h_{t, j, i}\right\}_{i=1}^{I}\right\}_{j=0}^{J}\right\}_{t=0}^{T}$, sequences of aggregate variables $\left\{L_{t}, K_{t}, Y_{t}\right\}_{t=0}^{T}$, government policies $\left\{\rho_{t}, \tau_{t}\right\}_{t=0}^{T}$, prices $\left\{w_{t}, r_{t}\right\}_{t=0}^{T}$ and transfers $\left\{\operatorname{tr}_{t}\right\}_{t=0}^{T}$ such that

1. given prices, bequests and initial conditions, households solve their maximization problem subject to the dynamic budget constraint in (30).

\footnotetext{
${ }^{10}$ In the U.S. system, pension benefits are linked to individual monthly earnings which are indexed and averaged over the life-cycle (Diamond and Gruber 1999). The replacement rate, however, is a decreasing function of monthly earnings such that the earnings related linkage is incomplete. By ignoring this earnings related linkage, we overstate the distortion of the labor-education-leisure decision induced by the pension system.
} 
2. Interest rates and wages satisfy equations (37) and (38).

3. Transfers are determined by

$$
t r_{t}=\frac{\sum_{j=0}^{J} \sum_{i=1}^{I} a_{t, j, i}\left(1-\varphi_{t-1, j-1}\right) N_{t-1, j-1, i}}{\sum_{j=0}^{J} \sum_{i=1}^{I} N_{t, j, i}}
$$

4. Government policies are such that the budget of the social security system is balanced every period, i.e. equation (40) holds $\forall t$.

5. Markets clear every period

$$
\begin{aligned}
L_{t} & =\sum_{j=0}^{j r-1} \sum_{i=1}^{I} \ell_{t, j, i} h_{t, j, i} N_{t, j, i} \\
K_{t+1} & =\sum_{j=0}^{J} \sum_{i=1}^{I} a_{t+1, j+1, i} N_{t, j, i} \\
Y_{t} & =\sum_{j=0}^{J} \sum_{i=1}^{I} c_{t, j, i} N_{t, j, i}+K_{t+1}-(1-\delta) K_{t} .
\end{aligned}
$$

6. The distribution of types in the economy is constant, $\Phi_{t}=\Phi$.

Definition 2. A stationary equilibrium is a competitive equilibrium in which aggregate variables grow at the same constant rate and individual variables are stationary.

\section{Calibration and Computation}

In this section we describe the calibration of the parameters and the computational procedure to solve the model. Our basic strategy is to specify the simplest model with endogenous labor supply (but without educational investment) at the beginning and add model elements step by step. We will occasionally refer to this first model as the "standard" model. ${ }^{11}$ Thus, we go from the simplest and computationally easiest model to the most involved and computationally

\footnotetext{
${ }^{11}$ We termed it "standard" because almost all quantitative studies on demographic change discussed in the introduction rely on physical capital only.
} 
most challenging one. Moreover, we redo all calculations for both pension system scenarios. To meet our calibration targets, we re-calibrate the models for every specification.

Our "standard" model is the exogenous growth specification without educational investment. Agents make only labor supply and consumption-saving decisions. In a first extension, we allow agents to invest into education but the rate of technical progress is still exogenous. Finally, we switch to the endogenous growth model with education.

To calibrate the model, we take data from the U.S. and assume that the U.S. is a closed economy. On the aggregate level, we take data from 1960 to 2004 from the National Income and Product Accounts. The empirically observed wage profiles are calculated using PSID data from 1968 to 1991 . The calibrated parameters are summarized in table 1 below. Details of our procedure are described in the following subsections.

\subsection{Demographics}

Population data are taken from and based on United Nations (2002). We use actual population data from 1950 onwards and base our projections on UN estimates until 2050. Afterwards, the forecasted values for the population until the final year of the simulation (2300) are based on the procedure used in Krüger and Ludwig (2007).

\subsection{Household Behavior}

The coefficient of relative risk aversion $\sigma$ is set to 2 , the pure time discount factor $\beta$ and the weight of consumption in the utility function $\phi$ vary across specifications (see table 1 with parameters) and are calibrated to match the empirically observed capital-output ratio and labor share, respectively. 


\subsection{Ability Profiles}

We endogenize education decisions of heterogenous agents such that model wage profiles resulting from human capital accumulation are consistent with empirically observed wage profiles. We do this mainly through the choice of the parameter vector $\left\{\zeta_{i}, \xi_{i}, \psi_{i}, \delta_{i}^{h}\right\}_{i=1}^{I}$. We determine these structural model parameters by indirect inference methods (Smith 1993; Gourieroux et al. 1993).

The methodology to generate the type-dependent lifetime wage profiles closely follows Fullerton and Rogers (1993) and Altig et al. (2001). We assume that individual wage profiles for each type can be approximated by a third-order age polynomial,

$$
w_{t, j, i}=w_{t} e^{\eta_{0, i}} e^{\left(\eta_{1, i}+g\right) j+\eta_{2, i} j^{2}+\eta_{3, i} j^{3}}
$$

where $j$ again denotes age, $i$ denotes the ability group and $g$ is an exogenously given rate of technical progress (here wage growth). The effect of age on individual earnings is given by the values of the $\eta$ coefficients.

We first regress the log of real hourly wages on age, age squared, age cubed, and interactions between age and age squared with education, gender, marital status and a dummy variable for a white agent. ${ }^{12}$ In the next step we use the coefficients from the previous regression to generate a fictitious lifetime earnings profile for each individual. ${ }^{13}$ These profiles are used to calculate the discounted present value of lifetime earnings by which we divide individuals into three different ability groups. Individuals with high lifetime earnings are classified as having

\footnotetext{
${ }^{12}$ We use a fixed effect panel regression to isolate the individual effects like innate ability, motivation or other unobserved characteristics that are constant over time.

${ }^{13}$ For this out of sample prediction we assume that education is constant at the highest level and the individual is married if she was married at least once during the observation period. Hourly wages are replaced by the their fictitious values only if they are not given in the data.
} 
high learning and earnings capacity.

Using these sub-samples we then run separate regressions of the form

$$
\log w_{j, i}=\eta_{0}+\eta_{1, i} j+\eta_{2, i} j^{2}+\eta_{3, i} j^{3}
$$

for each ability group to obtain the group specific intercepts $\left\{\eta_{0, i}\right\}_{i=1}^{I}$ and the coefficient vector $\vec{\eta}=\left\{\eta_{1, i}, \eta_{2, i}, \eta_{3, i}\right\}_{i=1}^{I}$ which determines the slope of the age polynomial. Here, $w_{j, i}$ is the de-trended real hourly wage rate. ${ }^{14}$ In order to exclude the problem of possibly different initial assets of individuals, we use only labor income (instead of total income including income from assets) and exclude all imputed observations. We further exclude observations with obvious inconsistencies in education, age, etc., observations with less than 240 and more than 4000 hours worked per year ${ }^{15}$, the lowest and highest percentile in hourly wages and people with less than 4 years of education.

Figure 2 presents the average hourly wages from the PSID used to recover the coefficients for the three ability groups. Our coefficients (see table 8 in appendix A.1) and the shape of the wage profiles are in line with others reported in the literature, especially with those obtained by Hansen (1993) and Altig et al. (2001).

We next determine the structural model parameters of the human capital technology. First, the group specific intercepts $\left\{\eta_{0, i}\right\}_{i=1}^{I}$ determine the relative human capital endowments for a newborn generation. The parameters are calculated as $\zeta_{i}=e^{\eta_{0, i}}$ and re-scaled such that the average newborn inherits $\mu$ human capital. As each ability group is weighted equally, we thereby also determine the time-invariant distribution, $\Phi$, of our model households. Second,

\footnotetext{
${ }^{14}$ In slight abuse of notation, we de-trend data by using the trend calculated from the sample and do not de-trend with the value of $g$ used below to calibrate exogenous technological progress in our simulation model.

${ }^{15}$ By excluding observations with less than 240 hours we exclude possible part time workers. The upper limit of 4000 hours is usually seen as a maximum amount of possible yearly working hours. See also Altig et al. (2001)
} 
Figure 2: PSID Wage Profiles

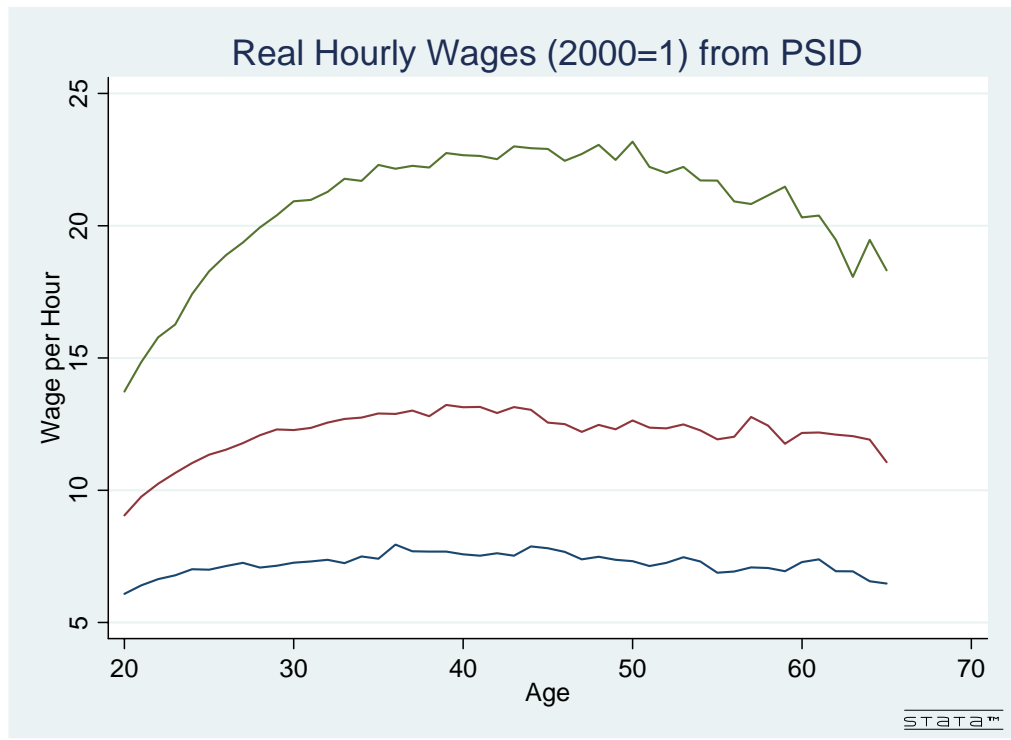

using data on wages simulated from our model, we run group specific regressions on the above age polynomial. The resulting coefficient vector $\overrightarrow{\hat{\eta}}=\left\{\hat{\eta}_{1, i}, \hat{\eta}_{2, i}, \hat{\eta}_{3, i}\right\}_{i=1}^{I}$ is a function of the structural model parameters $\left\{\xi_{i}, \psi_{i}, \delta_{i}^{h}\right\}_{i=1}^{I}$. Accordingly, the values of our structural model parameters are determined by minimizing the distance $\|\vec{\eta}-\vec{\eta}\|$, see subsection 4.7 for further details.

Throughout, we set the maximum age for educational investment $j h$ to 41 , the peak of the real de-trended hourly earnings of the medium ability group. This simplifying assumption allows us to match the empirical patterns of the observed productivity profiles. ${ }^{16}$ Without constraining $j h$ in this way our parsimonious specification of the human capital technology would not result in a decent fit to the data.

\footnotetext{
${ }^{16}$ The peak for the other two groups is 39 and 40 . As this is close to 41, we do not introduce a different upper bound on $j h$ for each ability group.
} 


\subsection{Growth Specification}

In the endogenous growth model we set the exogenous growth rate to zero and calibrate $\mu$ such that we match average GDP growth for the calibration period. We set $S_{1}=16$ and

$S_{2}=90$ and thereby assume that the knowledge of all citizens is used to produce average human capital.

In the exogenous model we set $\mu$ to zero and use an exogenously given labor productivity growth rate of $1.8 \%$ per year calibrated to match our data on TFP growth. This implies that in the exogenous growth model all generations start with the same initial human capital.

\subsection{Production}

For the capital share in production, $\alpha$, we take a value of 0.33 and assume that the depreciation rate of physical capital $\delta$ is $4 \%$ per year. Both numbers are standard in the literature and are therefore included as predetermined parameters.

\subsection{The Pension System}

In our benchmark scenario we fix contribution rates and adjust replacement rates of the pension system. We calculate contribution rates from NIPA-data from 1950-2004 and freeze the contribution rate of the year 2004 for all following years. Below, we also address the sensitivity of our results by simulating a version of the model with a constant replacement rate such that contribution rates have to adjust. 


\subsection{Computational Method}

We solve the model by assuming that the economy reaches a new steady state in the year 2300 . By that year, all transitional dynamics are completed by assumption. ${ }^{17}$ To get appropriate starting values, we assume that the economy was in an "old" steady state until the year 1950.

For a given set of structural model parameters, solution of the model is by outer and inner loop iterations. On the aggregate level (outer loop), the model is solved by guessing an initial time path of the aggregate labor share, the capital-output ratio, the growth rate of average human capital and bequests for all periods from $t=0$ until $T=351$. On the individual level (inner loop), we start in each iteration by setting the terminal values for consumption and human capital. Then we proceed by backward induction and iterate over these terminal values until convergence of these inner loops. In each outer loop, disaggregated variables are aggregated each period. We then update the sequences of the capital-output ratio, the labor share, the growth rates of human capital and bequests until convergence. Updating of these variables is by the modified Gauss-Seidel-Newton method developed in Ludwig (2007).

In addition, we solve for values of the structural model parameters by minimizing the distance between the respective model simulated values of variables and their empirical counterparts. In the most elaborate endogenous growth model we calibrate 12 parameters simultaneously to meet our targets on the aggregate and individual level. Values of all model parameters are summarized in table 1.

\section{Results}

In this section we present the results of our quantitative analysis. To develop intuition for our results on the demographic transition, we first perform a comparison between an artificial

\footnotetext{
${ }^{17}$ In fact, changes in variables which are constant in steady state are numerically irrelevant already around the year 2250.
} 
Table 1: Model Parameters

\begin{tabular}{|c|c|c|c|c|c|}
\hline & & Growth Scenario & Endogenous & Exo & nous \\
\hline & & Education & Yes & Yes & No \\
\hline Preferences & $\sigma$ & Relative Risk Aversion Parameter & 2 & 2 & 2 \\
\hline & $\beta$ & Pure Time Discount Factor & 0.97 & 0.99 & 0.97 \\
\hline & $\phi$ & Weight of Consumption & 0.78 & 0.81 & 0.70 \\
\hline Education & $\xi$ & Scaling Factor & 0.098 & 0.082 & - \\
\hline & & & 0.095 & 0.079 & - \\
\hline & & & 0.092 & 0.075 & - \\
\hline & $\psi$ & Curvature Parameter & 0.780 & 0.759 & - \\
\hline & & & 0.804 & 0.784 & - \\
\hline & & & 0.811 & 0.792 & - \\
\hline & $\delta^{h}$ & Depreciation Rate of & $1.2 \%$ & $1.2 \%$ & $0.0 \%$ \\
\hline & & Human Capital & $0.8 \%$ & $0.8 \%$ & $0.0 \%$ \\
\hline & & & $0.5 \%$ & $0.5 \%$ & $0.0 \%$ \\
\hline & $\zeta$ & Initial Relative Human & 1.46 & 1.46 & 1.46 \\
\hline & & Capital Endowment & 0.94 & 0.94 & 0.94 \\
\hline & & & 0.60 & 0.60 & 0.60 \\
\hline Growth & $\mu$ & Human Capital Bequest Factor & 1.38 & - & - \\
\hline & $\mathrm{g}$ & Exogenous Growth Rate & $0.0 \%$ & & \\
\hline Production & $\alpha$ & Share of Capital in Production & & & \\
\hline & $\delta$ & Depreciation Rate of Physical Capital & & & \\
\hline
\end{tabular}

initial steady state and the final steady state of our model. As the old age dependency ratio is higher in the final steady state, this comparison allows qualitative conclusions on the effects of demographic change across specifications. Next, we turn to the analysis of the transitional dynamics where we focus especially on the developments of major macroeconomic variables for the period 2005 to 2050 across growth scenarios and perform a welfare analysis of the effects of demographic change.

\subsection{Steady State Comparison}

In order to obtain some first insights into the long run effects of demographic change, we here compare two different steady states. The thought experiment is to choose an artificial 
"base" steady state year (2005) and compare it to the final steady state year in the future (2300). The exogenous driving force of the results is the increasing share of retirees and the shrinking working age population between steady states. The comparison allows us to get some intuition for the mechanics of the model as far as the qualitative effect of a different population structure on the economy is concerned. Furthermore, the steady state comparison enables us to perform a comparison across growth scenarios and thereby to examine whether the different assumptions behind these scenarios lead to any significant differences in simulation outcomes. All results in this section are derived by holding the social security contribution rate constant at the 2004 level.

Table 2 compares some key variables for the two steady states. As a summary statistic of the exogenous demographic variation across the two steady states, we report the old-age dependency ratio which is at $17 \%$ in the initial steady state and at $32 \%$ in the final steady state of the model.

Table 2: Steady State Results

\begin{tabular}{l|ccc|ccc} 
& \multicolumn{3}{|c|}{$\begin{array}{c}\text { Initial Steady State (2005) } \\
\text { OADR: 0.17 }\end{array}$} & \multicolumn{3}{c}{ Final Steady State (2300) } \\
OADR: 0.32
\end{tabular}

Note: $\gamma^{Y / N}$ denotes the growth rate of per capita output.

The results shown in the table are in line with the prediction of the simple model and we can draw a number of conclusions. First, in the standard model, as a consequence of the decreasing working age population, the capital-output ratio in the final steady state settles at a 
much higher level than the year 2005 steady state value. Interest rates are accordingly bound to decline by a non-negligible amount and effective wages to rise. The difference between steady state interest rates is at 2 percentage points.

Second, when we allow endogenous adjustment of education decisions but continue to work with the assumption of exogenous growth, the capital-output ratio still increases but the effect is much smaller than in the standard model. The difference between steady state interest rates is now at 0.6 percentage points, more than three times smaller than in the standard model. As derived in our simple model, relative shortage of the factor labor induces incentives to invest in human capital which dampens the "pure" demographic effects on the capital-output ratio. Our findings suggest that this effect may be quite large and that we may miss an important adjustment mechanism to demographic change if we ignore endogenous human capital formation.

Third, in the endogenous growth specification, the increase of human capital formation implies a higher long-run growth rate of 2.2 percent relative to an initial level of 1.8 percent. Accordingly, there will be large long-run welfare gains through the acceleration of human capital transmission which is induced by demographic change. Despite this difference in growth rates, almost no differences in capital-output ratios and interest rates to the exogenous growth specification with endogenous human capital formation can be observed.

\subsection{Transitional Dynamics}

In this section we concentrate on the transitional dynamics and divide our analysis into three parts. First, we analyze the behavior of several important aggregate variables. Second, we investigate the welfare consequences of demographic change for households living through the demographic transition. Finally, we look at the welfare consequences for generations already 
living in 2005.

\subsubsection{Aggregate Variables}

In figure 3 we show the evolution of the interest rate for the three growth scenarios. ${ }^{18}$ In the standard model without endogenous education adjustments, the interest rate decreases from an initial level of $7.4 \%$ in 2005 to $6.6 \%$ in 2050 , a difference of 0.8 percentage points. This magnitude is in line with results reported elsewhere in the literature, cf. Krüger and Ludwig (2007). In contrast, in the two models with education, the interest rate is expected to fall by only $0.2 \%$ percentage points. As in our earlier steady state comparison, this difference in the decrease of the interest rate between the exogenous and the endogenous growth models is large, at a factor of about 3. Furthermore, observe that the decrease of the rate of return is somewhat smaller in the endogenous growth model than in the exogenous growth model with education. This is a consequence of the intergenerational spill-over of human capital which increases effective labor, decreases the capital stock per efficiency unit and thereby stabilizes relatively more the rate of return (cf. our discussion of the simple model in subsection 2.5).

In figure 4 we depict the evolution of aggregate labor supply shares as the number of agents working relative to the total working age population. In the standard model, although aggregate labor supply decreases, hours worked per worker increase such that the labor supply shares increase slightly from roughly $68 \%$ to $70 \%$. Accordingly, the substitution effect of increasing wages is slightly stronger than the income effect. The increase of labor supply shares in the two models with endogenous human capital formation is slightly less pronounced. This is due to the existing trade-off between working, education and leisure in these models.

The difference between the two human capital augmented models can be explained by the

\footnotetext{
${ }^{18}$ Notice that level differences in the interest rate in 2005 across the growth/education scenarios are due to the fact that our calibration targets are averages of the 1960-2004 period and not the year specific values in 2005. Such differences in initial values can be observed in all following figures.
} 
Figure 3: Interest Rate

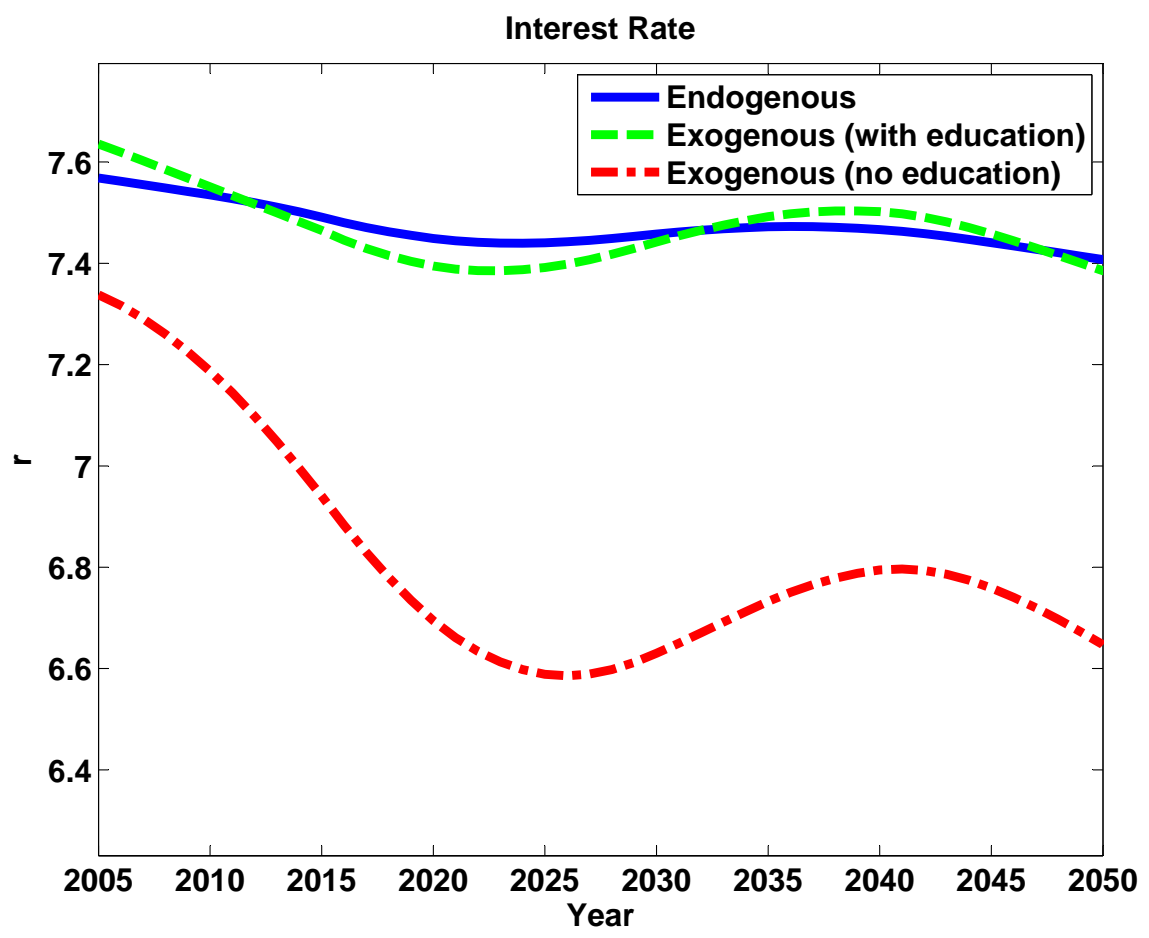

endogenous growth mechanism. Because agents will invest less time into education in the endogenous growth model (relative to the exogenous case), cf. the discussion of our simple model in subsection 2.5, they will spend more time on the labor market.

Finally, we focus on the evolution of the growth rate of GDP per capita shown in figure 5. When the U.S. aging process peaks in 2020, the growth rate of per capita GDP falls in the standard model from an above steady state level of $2.4 \%$ in 2005 to a below steady state level of $1.4 \%$ in 2020 , a decrease by roughly 1 percentage point. ${ }^{19}$ In contrast, in the exogenous growth model with education, the growth rate does only fall by 0.6 percentage points during the same period. Recall that this is only a transitional effect because the long-run steady state growth rates are identical in these two models. Endogenous growth does not alter the results much compared to the exogenous growth model with education. Only after 2030 the growth

\footnotetext{
${ }^{19}$ The high initial growth rate is a consequence of the past baby boom.
} 
rate is relatively higher due to the positive effect of increased education on the human capital received by newborns which ultimately leads to the relative increase of the long-run growth rate reported in subsection 5.1. Growth rates of consumption per capita display similar trends.

Figure 4: Labor Share

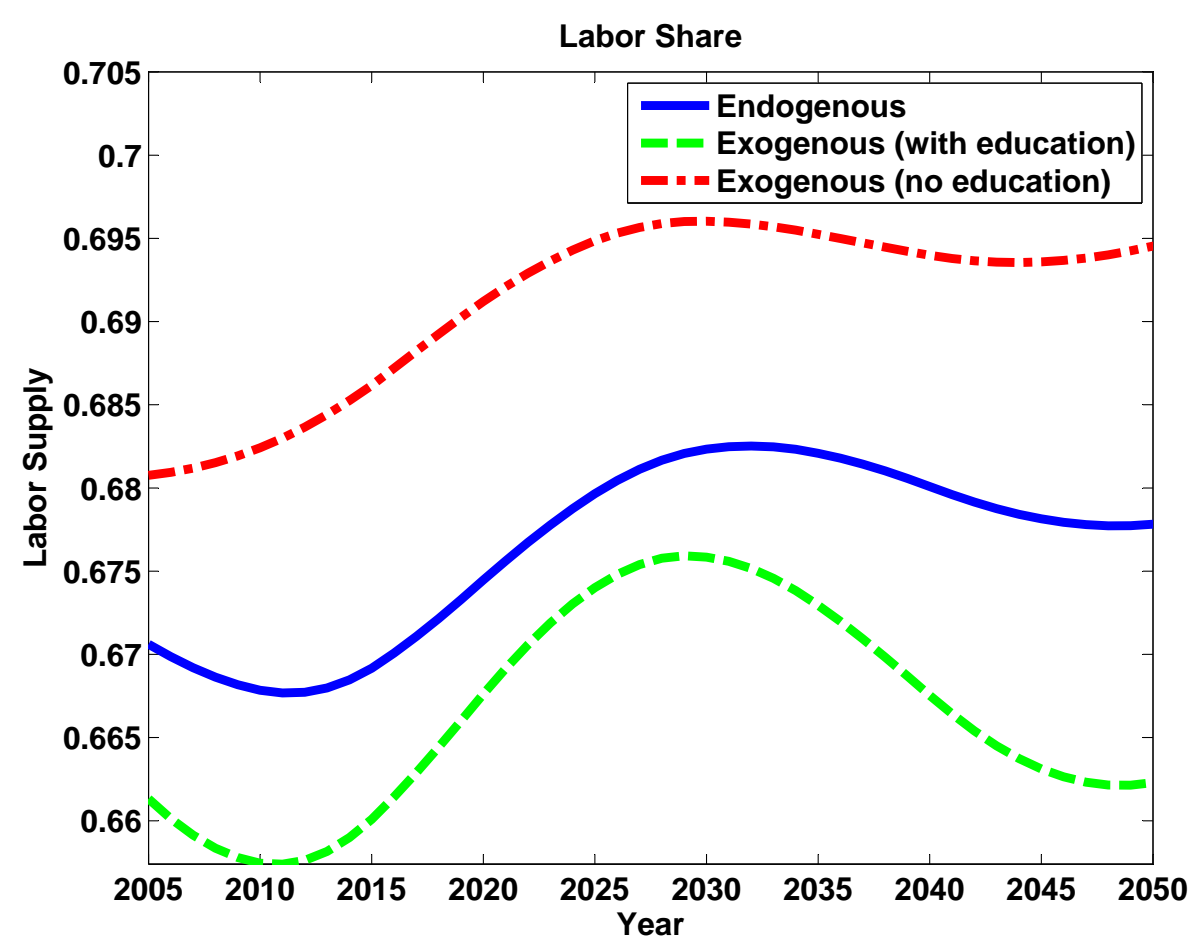

\subsubsection{Welfare Effects}

A household's welfare is affected by two consequences of demographic change. First, her lifetime utility changes because her own survival probabilities increase. Second, due to the demographic transition, she faces different factor prices, transfers from accidental bequests and replacement rates (or contribution rates) of the social security system than without changes in the demographic structure. Specifically, households face a path of declining interest rates, increasing wages and decreasing replacement rates, relative to the situation without a demographic transition. Additionally, in the endogenous growth model, households face different 
Figure 5: Growth of GDP per Capita

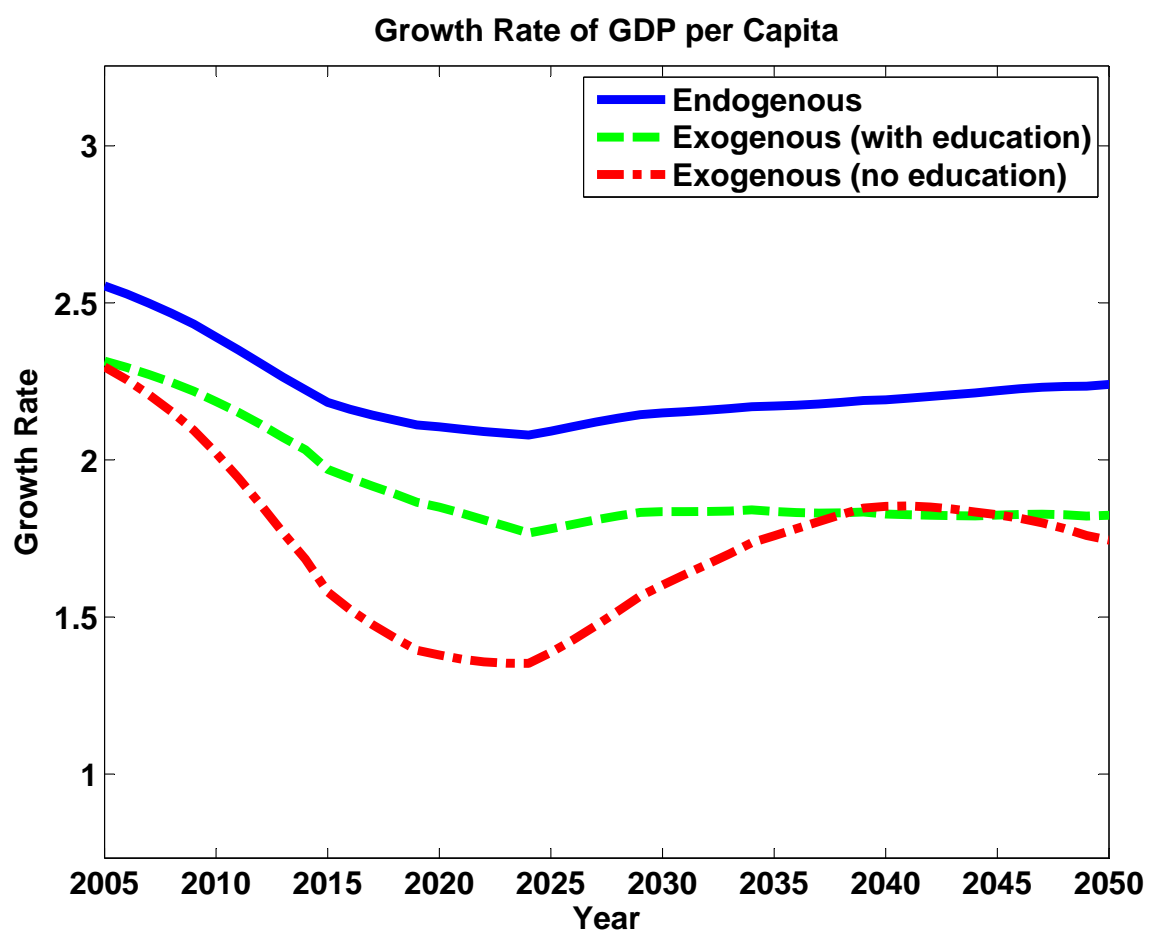

stocks of initial human capital levels at the beginning of their life. Below, we focus on the welfare effects for households already alive in 2005 for whom initial human capital levels are taken as given. Our welfare calculations are therefore not affected by changes in the intergenerational transmission of human capital.

We want to isolate the welfare consequences of the second effect. For this we compare lifetime utility of agents born and already alive in 2005 under two different scenarios. For both scenarios we fix a household's individual survival probabilities at their 2005 values. Of course, they fully retain their age-dependency. Then we solve each household's problem under two different assumptions about factor prices, transfers and social security replacement and contribution rates. When comparing welfare implications in different models, we use the parametrization of the respective model that results from calibration. ${ }^{20}$

\footnotetext{
${ }^{20}$ One may object that we thereby evaluate welfare consequences using different sets of preference parameters across model specifications. We do this because we have to recalibrate the model in order to meet our calibration targets (which results
} 
Let $\bar{V}_{t, j, i}$ denote lifetime utility of an agent born at time $t$, age $j$ and type $i$ facing the sequence of equilibrium prices, transfers and replacement rates as documented in the previous section, but constant 2005 survival probabilities, and let $\bar{V}_{t, j, i}^{2005}$ denote the lifetime utility of the same agent that faces prices, transfers and replacement rates that are held constant at their 2005 value. Finally, denote by $g_{t, j, i}^{c}$ the percentage increase in consumption (the consumption equivalent variation) that needs to be given to an agent with characteristics $t, j, i$ at each date in her remaining lifetime at fixed prices to make her as well off as under the situation with changing prices. Positive numbers of $g_{t, i, j}^{c}$ thus indicate that households obtain welfare gains from the general equilibrium effects of the demographic changes, negative numbers mean welfare losses. With our assumptions on preferences, $g_{t, i, j}^{c}$ can be calculated as

$$
g_{t, i, j}^{c}=\left(\frac{\bar{V}_{t, j, i}}{\bar{V}_{t, j, i}^{2005}}\right)^{\frac{1}{\phi(1-\sigma)}}-1 .
$$

Our first interest is in the numbers $g_{t=56, j=0, i}^{c}$, that is, the welfare consequences for newborn agents in $2005(t=56)$. These results are shown in table 3. We make several observations. First, observe that newborns gain from the changing demographics in the standard model, that is, the gains from increasing wages outweigh the losses incurred by decreasing rates of return. This finding is in line with the results reported in Krüger and Ludwig (2007). ${ }^{21}$ These welfare gains are around $0.4 \%$. Second, in the two models with endogenous education, welfare gains are higher than in the standard model because households are given an additional channel to adjust to the time varying demographic processes by investing more in their education. Third, welfare gains are lower in the endogenous growth/endogenous education than in the exogenous growth/endogenous education scenario. The reason for this finding is that the decrease of the

automatically in different parameter values). In appendix A.4 we present the same calculations using the parameters from the exogenous growth model with education, our "in-between" model variant, and thereby confirm that the qualitative results do not change using these alternative set of calibration parameters.

${ }^{21}$ As further shown in Ludwig et al. (2007) using a stylized OLG model without social security and with exogenous labor supply (and no education decision), welfare of newborns has to increase in dynamically efficient economies when the population growth rate decreases. These results are reminiscent of the serendipity theorem of Samuelson (1975), see also Michel and Pestieau (1993). 
rate of return and the corresponding increase in wages per efficiency unit of labor is lower in the endogenous growth specification, cf. figure 3. Consequently, individual households benefit relatively less from increasing wages in the endogenous growth model. Finally, in all models, agents with low productivity experience higher welfare gains. This effect comes through two channels. One is that agents with low levels of human capital receive proportionally more government transfers through bequests than high ability agents. The second effect comes through education. Agents with low innate abilities will initially choose lower education levels but will increase their educational investment proportionally more than high ability agents. ${ }^{22}$

Table 3: CEV for Generation Born in 2005

\begin{tabular}{lccc}
$\begin{array}{c}\text { Growth Scenario } \\
\text { Education }\end{array}$ & $\begin{array}{c}\text { Endogenous } \\
\text { Yes }\end{array}$ & $\begin{array}{c}\text { Exogenous } \\
\text { Yes }\end{array}$ & $\begin{array}{c}\text { Exogenous } \\
\text { No }\end{array}$ \\
\hline \hline & & & \\
\hline High & $0.4 \%$ & $0.9 \%$ & $0.2 \%$ \\
Medium & $0.7 \%$ & $1.3 \%$ & $0.4 \%$ \\
Low & $1.1 \%$ & $1.9 \%$ & $0.7 \%$ \\
\hline
\end{tabular}

Of particular interest is also how the welfare of all generations already alive in 2005 will be affected by demographic change. While newborn generations (and, more generally, young generations) benefit from increasing wages (despite decreasing returns) we expect that the lifetime utility of older (and thus asset-rich) generations will decrease because of the falling returns on capital and the decreasing retirement income in our scenario with constant contribution rates. The key question is then how the distribution of winners and losers varies across the three model specifications.

These results are shown in figures 6 through 8. In the model without education (figure 6), basically only newborn and very young generations gain. Almost all other agents will

\footnotetext{
${ }^{22}$ This is caused by the higher elasticity of education w.r.t changes in capital per effective worker for low type agents, cf. appendix A.3. Although the quantitative effects become small because differences in the slopes of the age productivity profiles are small, this conclusion of course holds if we set all transfers to zero (i.e. isolating the pure 'education' effect) and let households re-optimize.
} 
Figure 6: CEV for Exogenous Growth without Education

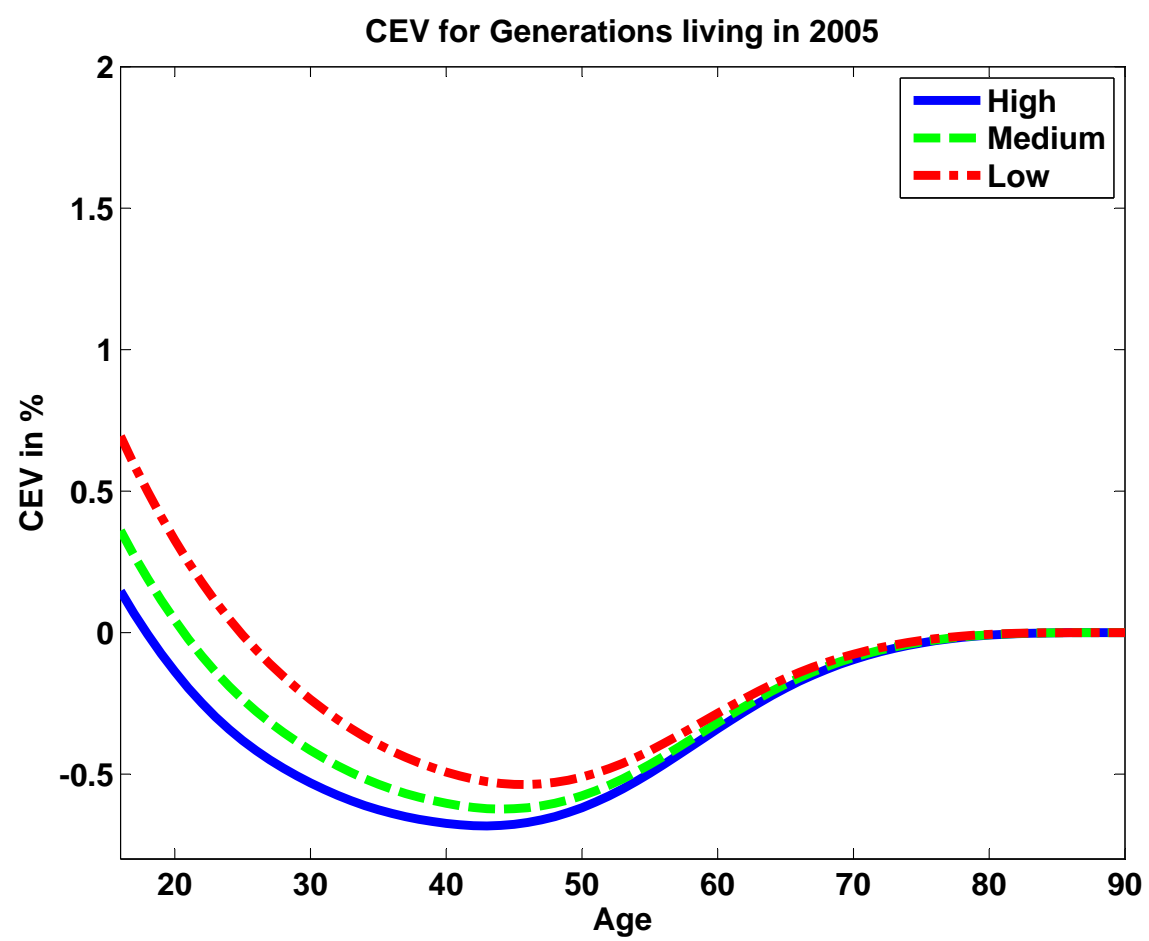

experience a fall in lifetime utility. Agents around 40 to 45 will incur the highest losses, at $-0.7 \%$ because these middle aged agents suffer the most from lower future pensions and decreasing capital income due to falling interest rates.

The results change remarkably if we consider the models with education (figures 7 and 8). There, the gains are more equally distributed with a much lower share of losers. Taking the medium ability group as a benchmark, the age limit separating losers and winners shifts up by 15 years. Moreover, the maximum losses are much lower, relative to the standard model. There are two main reasons for these differences in results. First, the change in interest rates and wages is smaller in the models with education. Thus, asset rich households are relatively less affected by falling interest rates. Second, households adjust their optimal education which is beneficial for welfare. Moreover, as the welfare gains of newborns reported above, the variation of welfare effects across all households economically alive in 2005 are 
Figure 7: CEV for Exogenous Growth with Education

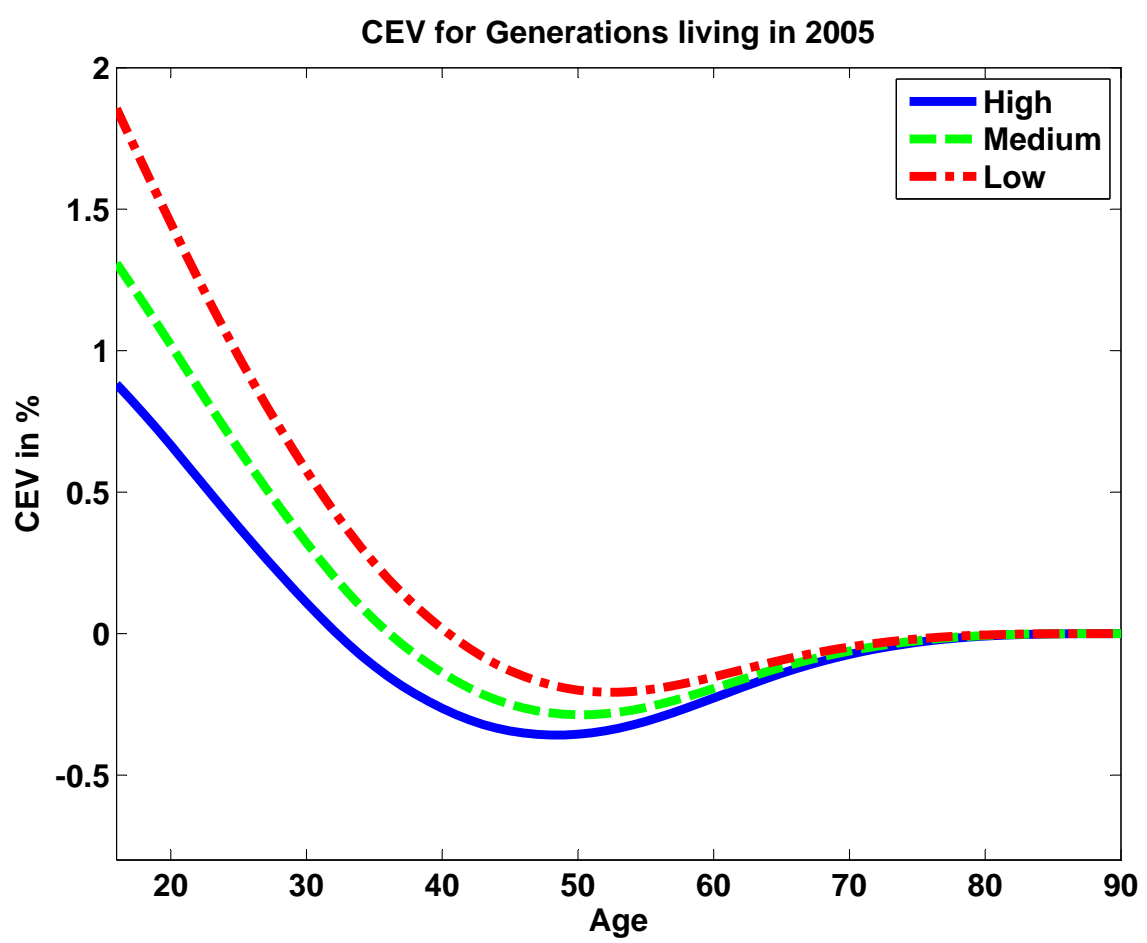

Table 4: Distribution of Welfare Changes and Maximum Losses

\begin{tabular}{lccc}
$\begin{array}{l}\text { Growth Scenario } \\
\text { Education }\end{array}$ & $\begin{array}{c}\text { Endogenous } \\
\text { Yes }\end{array}$ & $\begin{array}{c}\text { Exogenous } \\
\text { Yes }\end{array}$ & $\begin{array}{c}\text { Exogenous } \\
\text { No }\end{array}$ \\
\hline \hline & & & \\
\hline Percentage Winners & $37 \%$ & $39 \%$ & $11 \%$ \\
Maximum Loss CEV & $-0.21 \%$ & $-0.36 \%$ & $-0.68 \%$ \\
\hline
\end{tabular}

lower in the endogenous growth scenario. Therefore, welfare losses for older and asset rich households are also lower than in the scenario without the transmission of human capital. The reason is again the lower relative price reaction in the endogenous growth model, cf. figure 3.

To summarize the information in the earlier figures, table 4 reports the share of agents gaining and loosing and their maximum loss in terms of lifetime utility. We observe that the number of agents with losses is roughly three times higher in the models without education. In addition, the maximum losses are restricted to $-0.21 \%$ to $-0.36 \%$ compared to $-0.68 \%$ in the case with no education. 
Figure 8: CEV for Endogenous Growth with Education

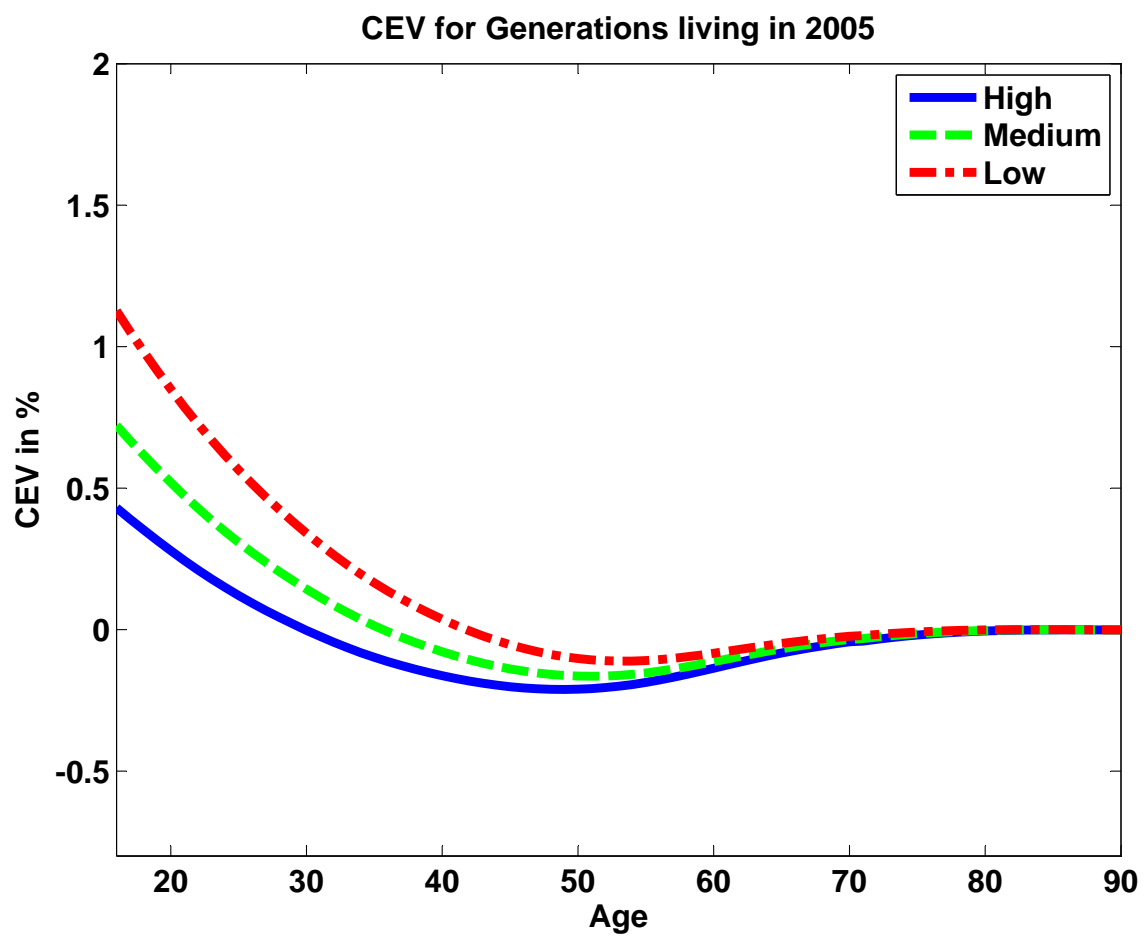

\subsubsection{Variations in Social Security}

In our analysis above we assumed that social security contribution rates are held constant at their 2004 levels and that replacement rates of the PAYG system decrease such as to balance the budget. Here, we examine how the choice of the future pension system affects our results and focus on the other extreme scenario where replacement rates are held constant and contribution rates have to be increased to balance the budget. As the two human capital augmented models yield similar insights, we focus on a comparison between the endogenous growth model with the standard model as the two polar cases considered earlier. ${ }^{23}$ As a further sensitivity analysis, we also report numbers on the welfare evaluation for an economy without social security.

From the steady state comparison in our simple model of section 2 we derived that we can

\footnotetext{
${ }^{23}$ Results on the exogenous growth/endogenous education scenario yield similar insights and are available upon request.
} 
expect lower long-run increases in the capital-output ratio (and correspondingly lower longrun decreases of the rate of return), lower increases in education and thereby lower growth rates in a scenario with constant replacement rates and increasing contribution rates. Table 5 reports the results of interest from our simulations. Compared to the scenario with constant contribution rates (cf. table 2), the long-run growth rate is 0.2 percentage points lower. This is the detrimental effect of taxation on growth. As a consequence of crowding out through the pension system, capital-output ratios are lower and interest rates are higher but these differences across social security scenarios are small in the endogenous growth model.

Table 5: Steady State Results (Constant Replacement Rates)

\begin{tabular}{|c|c|c|c|c|}
\hline & \multicolumn{2}{|c|}{$\begin{array}{c}\text { Initial Steady State (2005) } \\
\text { OADR: } 0.17\end{array}$} & \multicolumn{2}{|c|}{$\begin{array}{c}\text { Final Steady State (2300) } \\
\text { OADR: } 0.32\end{array}$} \\
\hline $\begin{array}{l}\text { Growth Scen. } \\
\text { Education }\end{array}$ & $\begin{array}{c}\text { Endogenous } \\
\text { Yes }\end{array}$ & $\begin{array}{c}\text { Exogenous } \\
\text { No }\end{array}$ & $\begin{array}{c}\text { Endogenous } \\
\text { Yes }\end{array}$ & $\begin{array}{c}\text { Exogenous } \\
\text { No }\end{array}$ \\
\hline $\begin{array}{l}\mathrm{K} / \mathrm{Y} \\
\mathrm{r} \\
\gamma^{Y / N}\end{array}$ & $\begin{array}{c}2.78 \\
7.9 \% \\
1.8 \%\end{array}$ & $\begin{array}{l}2.71 \\
8.2 \% \\
1.8 \%\end{array}$ & $\begin{array}{c}2.88 \\
7.4 \% \\
2.0 \%\end{array}$ & $\begin{array}{l}3.10 \\
6.6 \% \\
1.8 \%\end{array}$ \\
\hline
\end{tabular}

Note: $\gamma^{Y / N}$ denotes the growth rate of per capita output.

As shown in figure 9, the rate of return initially decreases stronger in the scenario with constant replacement rates than in the scenario with constant contribution rates. It is only after 2030 that the crowding out effects on private savings dominate and that the rate of return decreases by less in the constant replacement rate scenario. For the standard model this difference between curves during the observation period is small when compared to the relatively strong effect between the social security scenarios under endogenous growth. The reason is that in the endogenous growth model not only labor supply but also educational decisions and thus productivity growth is affected. The higher growth rate of human capital due to more education in the fixed contribution rate scenario translates into higher output growth which keeps the capital-output ratio low and stabilizes the interest rate on a relatively 
Figure 9: Rate of Return (Constant Replacement Rates)

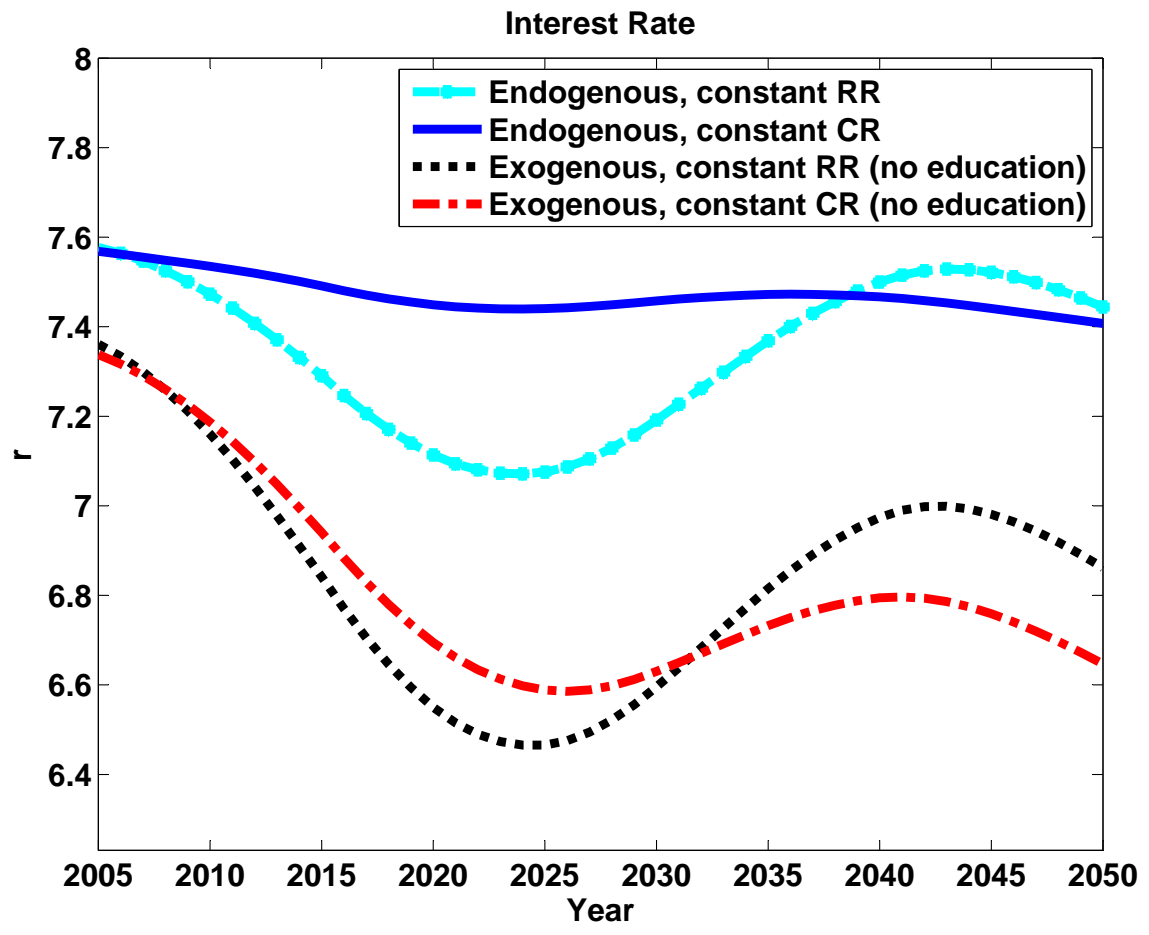

higher level. Differences in taxation are now magnified through the additional reaction of education. In terms of general equilibrium prices, the two models (exogenous and endogenous growth) are therefore closer to each other when replacement rates are held constant than under the opposite social security scenario which we analyzed in the previous subsections.

Consequently, differences across models in welfare gains (losses) for economically newborns in 2005 are also not as pronounced as in the scenario with constant contribution rates (cf. table 6 ). Due to the increasing contribution rates (and decreasing net wages) newborns experience welfare losses in the order of magnitude of $-2 \%$. Again, welfare losses are lower for low types (not shown) and lower in the two human capital augmented models but, as expected, welfare differences are not as pronounced as reported earlier. Furthermore, notice that all generations alive in 2005 loose from the effects of demographic change under constant replacement rates because of the increases in contribution rates. Comparing these welfare losses to 
the gains reported earlier exemplifies the potential benefits from reforming social security that are especially high when households react by increasing their education.

Table 6: Welfare Evaluation for Constant Replacement Rates

\begin{tabular}{lcc}
$\begin{array}{l}\text { Growth Scenario } \\
\text { Education }\end{array}$ & $\begin{array}{c}\text { Endogenous } \\
\text { Yes }\end{array}$ & $\begin{array}{c}\text { Exogenous } \\
\text { No }\end{array}$ \\
\hline \hline & & \\
\hline CEV $_{0}$ Medium Type & $-1.8 \%$ & $-2.2 \%$ \\
Percentage Winners & $0 \%$ & $0 \%$ \\
Maximum Loss & $-1.8 \%$ & $-2.2 \%$ \\
\hline
\end{tabular}

We conclude our discussion on the role of social security by presenting results of the welfare evaluation for an economy without social security in table 7 . When compared to the benchmark scenario with constant replacement rates the detrimental effects of decreasing pension payments on welfare of the middle aged are missing and this population group is only negatively affected by decreasing returns on their retirement savings. Consequently, modeling a social security free economy leads to an overestimation of the fraction of winners from demographic change. This is especially true for the endogenous growth scenario where welfare losses almost disappear.

Table 7: Welfare Evaluation without Social Security

\begin{tabular}{lcc}
$\begin{array}{l}\text { Growth Scenario } \\
\text { Education }\end{array}$ & $\begin{array}{c}\text { Endogenous } \\
\text { Yes }\end{array}$ & $\begin{array}{c}\text { Exogenous } \\
\text { No }\end{array}$ \\
\hline \hline & & \\
\hline CEV $_{0}$ Medium Type & $0.8 \%$ & $0.7 \%$ \\
Percentage Winners & $74 \%$ & $25 \%$ \\
Maximum Loss & $-0.02 \%$ & $-0.4 \%$ \\
\hline
\end{tabular}

\section{Conclusions}

This paper asks whether human capital adjustments play a significant role to address the consequences of demographic change in the U.S. economy over the coming decades. We 
find that increased educational investments substantially mitigate the macroeconomic impact of demographic change with profound implications for individual welfare. As labor will be relatively scarce and capital will be relatively abundant in an aging society, interest rates will fall but the effects will be much smaller once we account for changes in educational decisions. For the U.S., our simulations predict that the rate of return will fall by only 0.2 percentage points until 2050 with education, compared to 0.7 percentage points in the standard model. We do not find that making growth endogenous has a large effect on relative factor prices in the period of the demographic transition. Adjustments of relative prices are very similar, irrespective of the growth mechanism as long as education is included. In the long-run, however, we find that endogenous growth through human capital transmission will contribute to an increase of the growth rate of labor productivity by 0.2 to 0.4 percentage points.

We also document that the welfare consequences from the increase in wages and declines in rates of return can be substantial, in the order of up to $1 \%$ in lifetime consumption for newborns in 2005. These welfare gains for newborns however only come along if social security contribution rates are held constant at current levels. Households that have already accumulated assets, on the other hand, loose from the decline in rates of return. We also find that newborn low ability agents experience slightly higher welfare gains than high ability agents. More importantly, we find that welfare gains are substantially higher in the human capital augmented models relative to the standard model. The overall mass of agents alive in 2005 that benefit from demographic change increases from $11 \%$ to almost $40 \%$ when we move from the standard model to the human capital augmented models. At the same time, the maximum loss decreases from $-0.7 \%$ to $-0.4 \%(-0.2 \%)$ in the model with endogenous education (and endogenous growth). We therefore conclude that appropriately accounting for endogenous education decisions is key for a quantitative evaluation of the welfare effects of 
demographic change.

Our analysis shows that reforming social security systems by reducing future tax burdens provides important incentives for welfare improving accumulation of human capital. We have however ignored other policy measures, in particular education policy, and we have only focused on secondary and tertiary education. Furthermore, we have operated in a frictionless environment where all endogenous education adjustments are driven by relative price changes. In our future research we plan to investigate more deeply the scope for welfare improving education policy in aging societies if market frictions may prevent such automatic adjustments. 


\section{A Appendix}

\section{A.1 PSID-Profiles}

Table 8: Regression Coefficients

\begin{tabular}{c|cccc} 
type & constant & age & age $^{2}$ & age $^{3}$ \\
\hline \hline high & 1.534385 & 0.089528 & -0.001656 & $8.76 \mathrm{E}-06$ \\
mid & 1.090603 & 0.079985 & -0.001476 & $8.07 \mathrm{E}-06$ \\
low & 0.637634 & 0.068196 & -0.001238 & $6.86 \mathrm{E}-06$
\end{tabular}

\section{A.2 Analytical Solutions of the Simple Model}

Rewriting equations (23) for steady state education and capital stock gives

$$
F_{1}\left(k, e ; \gamma^{N}, \tau\right)=\Omega\left(e, \gamma^{N}, \tau\right)^{\frac{1}{1-\alpha}}-k
$$

(50) $F_{2}\left(k, e ; \gamma^{N}, \tau\right)=c k^{\frac{1-\alpha}{1-\psi}}-e$

$$
\begin{aligned}
c & \equiv\left[\omega \xi \psi \frac{\gamma^{A}}{\alpha}\right]^{\frac{1}{1-\psi}} \\
\Omega\left(e, \gamma^{N}, \tau\right) & \equiv \frac{\alpha(1-\alpha) \beta(1-e)(1-\tau)}{\gamma^{A}\left[(\alpha(1+\beta)+(1-\alpha) \tau)(1-e) \gamma^{N} \gamma^{h}+\omega(1+\alpha \beta)(1+g(e))\right]} .
\end{aligned}
$$

Changes in $k$ and $e$ (holding $\tau$ fixed) caused by changes in $\gamma^{N}$ are given by

$$
\left[\begin{array}{c}
\frac{\partial k}{\partial \gamma^{N}} \\
\frac{\partial e}{\partial \gamma^{N}}
\end{array}\right]=-\left[\begin{array}{cc}
\frac{\partial F_{1}(\cdot)}{\partial k} & \frac{\partial F_{1}(\cdot)}{\partial e} \\
\frac{\partial F_{2}(\cdot)}{\partial k} & \frac{\partial F_{2}(\cdot)}{\partial e}
\end{array}\right]^{-1}\left[\begin{array}{c}
\frac{\partial F_{1}}{\partial \gamma^{N}} \\
\frac{\partial F_{2}}{\partial \gamma^{N}}
\end{array}\right]
$$

where this is then

$$
\left[\begin{array}{c}
\frac{\partial k}{\partial \gamma^{N}} \\
\frac{\partial e}{\partial \gamma^{N}}
\end{array}\right]=-\left[\begin{array}{cc}
-1 & \frac{1}{1-\alpha} \Omega^{\frac{1}{1-\alpha}-1} \frac{\partial \Omega}{\partial e} \\
\frac{1-\alpha}{1-\psi} c k^{\frac{1-\alpha}{1-\psi}-1} & -1
\end{array}\right]^{-1}\left[\begin{array}{c}
\frac{1}{1-\alpha} \Omega^{\frac{1}{1-\alpha}-1} \frac{\partial \Omega}{\partial \gamma^{N}} \\
0
\end{array}\right]
$$

Solving the above system gives

$$
\left[\begin{array}{c}
\frac{\partial k}{\partial \gamma^{N}} \\
\frac{\partial e}{\partial \gamma^{N}}
\end{array}\right]=-(\operatorname{det} J)^{-1}\left[\begin{array}{cc}
-1 & -\frac{1}{1-\alpha} \Omega^{\frac{1}{1-\alpha}-1} \frac{\partial \Omega}{\partial e} \\
-\frac{1-\alpha}{1-\psi} c k^{\frac{1-\alpha}{1-\psi}-1} & -1
\end{array}\right]\left[\begin{array}{c}
\frac{1}{1-\alpha} \Omega^{\frac{1}{1-\alpha}-1} \frac{\partial \Omega}{\partial \gamma^{N}} \\
0
\end{array}\right]
$$


with

$$
\operatorname{det} J=\left[1-\frac{1}{1-\alpha} \Omega^{\frac{1}{1-\alpha}-1} \frac{\partial \Omega}{\partial e} \frac{1-\alpha}{1-\psi} c k^{\frac{1-\alpha}{1-\psi}-1}\right]
$$

Rewriting the system gives

$$
\left[\begin{array}{c}
\frac{\partial k}{\partial \gamma^{N}} \\
\frac{\partial e}{\partial \gamma^{N}}
\end{array}\right]=-(\operatorname{det} J)^{-1}\left[\begin{array}{c}
-\frac{1}{1-\alpha} \Omega^{\frac{1}{1-\alpha}-1} \frac{\partial \Omega}{\partial \gamma^{N}} \\
-\frac{1-\alpha}{1-\psi} c k^{\frac{1-\alpha}{1-\psi}-1} \frac{1}{1-\alpha} \Omega^{\frac{1}{1-\alpha}-1} \frac{\partial \Omega}{\partial \gamma^{N}}
\end{array}\right]
$$

As we can rewrite $(52)$ as

$$
\Omega\left(e, \gamma^{N}, \tau\right) \equiv \frac{\alpha(1-\alpha) \beta(1-\tau)}{\gamma^{A}\left[(\alpha(1+\beta)+(1-\alpha) \tau) \gamma^{N} \gamma^{h}+\omega(1+\alpha \beta) \frac{(1+g(e))}{1-e}\right]}
$$

it can be immediately seen that for exogenous growth $\left(\gamma^{h}=1\right) \frac{\partial \Omega}{\partial e}<0$ and $\frac{\partial \Omega}{\partial \gamma^{N}}<0$ holds. It is also obvious that replacing $\gamma^{h}$ with $\mu(1+g(e))$ does not change the sign of the derivative. Hence it follows that $\operatorname{det} J>0$ and thus $\frac{\partial k}{\partial \gamma^{N}}<0$ and $\frac{\partial e}{\partial \gamma^{N}}<0$ is true for endogenous and exogenous growth.

By linking pension payments to current wages (i.e. we hold the replacement rate constant), the contribution rate $\tau$ to the social security system will increase as the society ages (see equation 15). Since $\operatorname{sgn}\left(\frac{\partial \Omega}{\partial \gamma^{N}}\right)=\operatorname{sgn}\left(\frac{\partial \Omega}{\partial \tau}\right)$ we get immediately $\frac{\partial k}{\partial \tau}<0$ and $\frac{\partial e}{\partial \tau}<0$.

Unfortunately, repeating the comparative statics from above but letting the contribution rate $\tau$ adjust does not allow to draw clear cut conclusions. This is because the decisive part of the derivative $\frac{\partial \Omega}{\partial \gamma^{N}}=\left(\frac{\partial \Omega}{\partial \gamma^{N}}\right)^{D}+\frac{\partial \Omega}{\partial \tau} \frac{\partial \tau}{\partial \gamma^{N}}$ has a negative part $\left(\frac{\partial \Omega}{\partial \gamma^{N}}\right)^{D}$ and a positive part $\frac{\partial \Omega}{\partial \tau} \frac{\partial \tau}{\partial \gamma^{N}}$. Thus, we can only show that the effect is "less negative" which implies that adjusting the contribution rate has a dampening effect on the increase of $k$ and $e$ but we cannot determine the sign any more. 


\section{A.3 Elasticity of Educational Decision}

In steady state, equation (22) for education can be written as

$$
\begin{aligned}
e & =\left[\omega \xi \psi \frac{\gamma^{A}}{\alpha} k^{1-\alpha}\right]^{\frac{1}{1-\psi}} \\
& =\left(\frac{\omega \xi \psi \gamma^{A}}{\alpha}\right)^{\frac{1}{1-\psi}} k^{\frac{1-\alpha}{1-\psi}}
\end{aligned}
$$

The elasticity of education w.r.t. changes in $k$ is given by

$$
\eta_{e, k}=\frac{\partial e}{\partial k} \frac{k}{e}=\frac{1-\alpha}{1-\psi}>0
$$

Obviously, the elasticity $\eta$ increases with $\psi$. Because in our calibration low type agents have higher values of $\psi$ than high type agents, they increase their educational investment relatively more.

\section{A.4 Welfare Evaluation using alternative Parameters}

In this subsection we report the results or the welfare evaluation using the parameters obtained from the exogenous growth model. Note that if we compute the CEV of the endogenous and exogenous model without education using the parameters from the exogenous model with education we observe relative welfare losses. This is not surprising because a rising $\beta$ in combination with falling interest rates (which is the case here) causes relative welfare losses. The change in $\phi$ plays only a minor role.

Table 9: CEV for Generation Born in 2005 (Parameters Exogenous Growth Model)

\begin{tabular}{llccc} 
SS-Scenario & $\begin{array}{l}\text { Growth Specification } \\
\text { Education }\end{array}$ & $\begin{array}{c}\text { Endogenous } \\
\text { Yes }\end{array}$ & $\begin{array}{c}\text { Exogenous } \\
\text { Yes }\end{array}$ & $\begin{array}{c}\text { Exogenous } \\
\text { No }\end{array}$ \\
\hline \hline \multirow{3}{*}{ Fixed CR } & & & & \\
& High & $-0.2 \%$ & $0.9 \%$ & $-1.4 \%$ \\
& Medium & $0.1 \%$ & $1.3 \%$ & $-1.2 \%$ \\
& Low & $0.6 \%$ & $1.9 \%$ & $-0.9 \%$ \\
\hline
\end{tabular}




\section{References}

Aghion, P., E. Caroli, and C. García-Peñalosa (1999). Inequality and Economic Growth: The Perspective of the New Growth Theories. Journal of Economic Literature 37(4), $1615-1660$.

Aghion, P. and P. Howitt (1992). A Model of Growth through Creative Destruction. Econometrica $60(2), 323-351$.

Altig, D., A. J. Auerbach, L. J. Kotlikoff, K. A. Smetters, and J. Walliser (2001). Simulating Fundamental Tax Reform in the United States. American Economic Review 91(3), 574594.

Attanasio, O., S. Kitao, and G. L. Violante (2007). Global Demographic Trends and Social Security Reform. Journal of Monetary Economics 54(1), 144-198.

Auerbach, A. J. and L. J. Kotlikoff (1987). Dynamic Fiscal Policy. Cambridge: Cambridge University Press.

Börsch-Supan, A., A. Ludwig, and J. Winter (2006). Ageing, Pension Reform and Capital Flows: A Multi-Country Simulation Model. Economica 73, 625-658.

Boucekkine, R., D. de la Croix, and O. Licandro (2002). Vintage Human Capital, Demographic Trends, and Endogenous Growth. Journal of Economic Theory 104, 340-375.

Bouzahzah, M., D. de la Croix, and F. Docquier (2002). Policy Reforms and Growth in Computable OLG Economies. Journal of Economic Dynamics and Control 26, 20932113.

de la Croix, D. and O. Licandro (1999). Life Expectancy and Endogenous Growth. Economics Letters 65, 255-263.

De Nardi, M., S. Imrohoroglu, and T. J. Sargent (1999). Projected U.S. Demographics and Social Security. Review of Economic Dynamics 2(1), 575-615. 
Diamond, P. and J. Gruber (1999). Social Security and Retirement in the United States. In J. Gruber and D. Wise (Eds.), Social Security and Retirement Around the World, Chapter 11, pp. 437-474. Chicago: University of Chicago Press.

Echevarria, C. A. and A. Iza (2006). Life Expectancy, Human Capital, Social Security and Growth. Journal of Public Economics 90, 2324-2349.

Fougère, M. and M. Mérette (1999). Population Ageing and Economic Growth in Seven OECD Countries. Economic Modelling 16, 411-427.

Fullerton, D. and D. Rogers (1993). Who Bears the Lifetime Tax Burden? Washington DC: Brookings Institution Press.

Gourieroux, C., A. Monfort, and E. Renault (1993). Indirect Inference. Journal of Applied Econometrics 8, S85-S118.

Grossman, G. and E. Helpman (1991). Innovation and growth in the global economy. Cambridge, MA: MIT Press.

Hansen, G. D. (1993). The Cyclical and Secular Behaviour of the Labour Input: Comparing Efficiency Units and Hours Worked. Journal of Applied Econometrics 8(1), 71-80.

Heckman, J. and P. Carneiro (2003). Human Capital Policy. NBER Working Paper 9495.

Heckman, J., L. Lochner, and C. Taber (1998). Explaining Rising Wage Inequality: Explorations with a Dynamic General Equilibrium Model of Labor Earnings with Heterogenous Agents. Review of Economic Dynamics 1, 1-58.

Heer, B. and A. Irmen (2007). Population, Pensions, and Endogenous Economic Growth. Working Paper.

Heijdra, B. J. and W. E. Romp (2007). A Life-Cycle Overlapping-Generations Model of the Small Open Economy. Oxford Economic Papers. forthcoming.

Hendriks, L. (1999). Taxation and long-run growth. Journal of Monetary Economics 43, 
$411-434$.

Huang, H., S. Imrohoroglu, and T. J. Sargent (1997). Two Computations to Fund Social Security. Macroeconomic Dynamics 1(1), 7-44.

Huggett, M., G. Ventura, and A. Yaron (2006). Human Capital and Earnings Distribution Dynamics. Journal of Monetary Economics 53, 265-290.

Huggett, M., G. Ventura, and A. Yaron (2007). Sources of Lifetime Inequality. Working Paper.

Keane, M. P. and K. I. Wolpin (1997). The Career Decisions of Young Men. Journal of Political Economy 105(3), 473-521.

Krüger, D. and A. Ludwig (2007). On the Consequences of Demographic Change for Rates of Returns to Capital, and the Distribution of Wealth and Welfare. Journal of Monetary Economics 54(1), 49-87.

Lucas, R. E. (1988). On the Mechanics of Economic Development. Journal of Monetary Economics 22, 3-42.

Ludwig, A. (2007). The Gauss-Seidel-Quasi-Newton Method: A Hybrid Algorithm for Solving Dynamic Economic Models. Journal of Economic Dynamics and Control 31(5), $1610-1632$.

Ludwig, A., D. Krüger, and A. Börsch-Supan (2007). Demographic Change, Relative Factor Prices, International Capital Flows, and Their Differential Effects on the Welfare of Generations. NBER Working Paper 13185.

Michel, P. and P. Pestieau (1993). Population Growth and Optimality: When Does Serendipity Hold? Journal of Population Economics 6(4), 353-362.

Romer, P. M. (1990). Endogenous Technological Change. Journal of Political Economy 98(5), S71-S102. 
Sadahiro, A. and M. Shimasawa (2002). The Computable Overlapping Generations Model with Endogenous Growth Mechanism. Economic Modelling 20, 1-24.

Samuelson, P. a. (1975). The Optimum Growth Rate of Population. International Economic Review 16(3), 531-537.

Smith, A. A. (1993). Estimating Nonlinear Time-Series Models Using Simulated Vector Autoregressions. Journal of Applied Econometrics 8, S63-S84.

Storesletten, K. (2000). Sustaining Fiscal Policy through Immigration. Journal of Political Economy 108(2), 300-323.

United Nations (2002). World Population Prospects: The 2002 Revision. United Nations Population Division. New York: United Nations. 


\section{Discussion Paper Series}

Mannheim Research Institute for the Economics of Aging Universität Mannheim

To order copies, please direct your request to the author of the title in question.

\begin{tabular}{|c|c|c|c|}
\hline Nr. & Autoren & Titel & Jahr \\
\hline $139-07$ & Hendrik Jürges & $\begin{array}{l}\text { Does ill health affect savings intentions? } \\
\text { Evidence from SHARE }\end{array}$ & 07 \\
\hline $140-07$ & Hendrik Jürges & $\begin{array}{l}\text { Health inequalities by education, income, and } \\
\text { wealth: a comparison of } 11 \text { European countries } \\
\text { and the US }\end{array}$ & 07 \\
\hline 141-07 & Hendrik Jürges & $\begin{array}{l}\text { Healthy minds in healthy bodies. An } \\
\text { international comparison of education-related } \\
\text { inequality in physical health among older adults }\end{array}$ & 07 \\
\hline $142-07$ & $\begin{array}{l}\text { Karsten Hank, } \\
\text { Stephanie Stuck }\end{array}$ & $\begin{array}{l}\text { Volunteer Work, Informal Help, and Care among } \\
\text { the 50+ in Europe: Further Evidence for 'Linked' } \\
\text { Productive Activities at Older Ages }\end{array}$ & 07 \\
\hline $143-07$ & Jürgen Maurer & $\begin{array}{l}\text { Assessing Horizontal Equity in Medication } \\
\text { Treatment Among Elderly Mexicans: Which } \\
\text { Socioeconomic Determinants Matter Most? }\end{array}$ & 07 \\
\hline $144-07$ & Jürgen Maurer & $\begin{array}{l}\text { Socioeconomic and Health Determinants of } \\
\text { Health Care Utilization Among Elderly } \\
\text { Europeans: A Semiparametric Assessment of } \\
\text { Equity, Intensity and Responsiveness for Ten } \\
\text { European Countries }\end{array}$ & 07 \\
\hline $145-07$ & Jürgen Maurer & $\begin{array}{l}\text { Modelling socioeconomic and health } \\
\text { determinants of health care use: A } \\
\text { semiparametric approach }\end{array}$ & 07 \\
\hline $146-07$ & $\begin{array}{l}\text { Jérome Adda, James } \\
\text { Banks, Hans-Martin } \\
\text { von Gaudecker }\end{array}$ & $\begin{array}{l}\text { The Impact of Income Shocks on Health: } \\
\text { Evidence from Cohort Data }\end{array}$ & 07 \\
\hline $147-07$ & $\begin{array}{l}\text { Klaus Jäger, } \\
\text { Wolfgang Kuhle }\end{array}$ & $\begin{array}{l}\text { The Optimum Growth Rate for Population } \\
\text { Reconsidered }\end{array}$ & 07 \\
\hline $148-07$ & $\begin{array}{l}\text { Axel Börsch-Supan, } \\
\text { Ismail Düzgün, } \\
\text { Matthias Weiss }\end{array}$ & $\begin{array}{l}\text { Age and Productivity in Work Teams: Evidence } \\
\text { from the Assembly Line }\end{array}$ & 07 \\
\hline $149-07$ & Matthias Weiss & Sick Leave and the Composition of Work Teams & 07 \\
\hline $150-07$ & Matthias Weiss & Are Age-Diverse Work Teams Better? & 07 \\
\hline 151-07 & $\begin{array}{l}\text { Alexander Ludwig, } \\
\text { Thomas Schelkle, } \\
\text { Edgar Vogel }\end{array}$ & $\begin{array}{l}\text { Demographic Change, Human Capital and } \\
\text { Endogenous Growth }\end{array}$ & 07 \\
\hline
\end{tabular}

